\title{
PROMISE AND PERIL IN IMPLEMENTING PAY-FOR-PERFORMANCE
}

\section{Michael Beer and Mark D. Cannon}

Why would managers abandon pay-for-performance plans they initiated with great hopes? Why would employees celebrate this decision? This article explores why managers made their decisions in 12 of 13 pay-for-performance "experiments" at Hewlett-Packard in the mid-1990s. We find that managers thought the costs of these programs to be higher than the benefits. Alternative managerial practices such as effective leadership, clear objectives, coaching, or training were thought a better investment. Despite the undisputed instrumentality of pay-for-performance to motivate, little attention has been given to whether the benefits outweigh the costs or the "fit" of these programs with high-commitment cultures like Hewlett-Packard was at the time. (C) 2004 Wiley Periodicals, Inc.

\section{Introduction}

Immense pressure for higher performance has led corporations to search continually for managerial practices that will enhance competitiveness. An increasingly large number of corporations have explored how rewards, particularly money, could be linked to desired behavior and/or performance outcomes to improve effectiveness (Gerhart \& Rynes, 2003; Pfeffer, 1998; Rigby, 2001). This has led to widespread and growing development of payfor-performance plans (Schuster \& Zingheim, 1992). For example, a survey of 1,681 companies indicated that $61 \%$ had implemented variable compensation systems (Hein, 1996).

The powerful role that financial incentives can play in influencing behavior has been widely acknowledged since ancient times (Peach \& Wren, 1992). Early motivation theories such as expectancy theory (Vroom, 1964) have demonstrated intuitive appeal, and its basic components have received empirical support (Van Eerde \& Thierry, 1996). In addition, decades of empirical research in a variety of areas indicate that financial incentives are a potent motivator. An examination of studies of pay-for-performance programs suggests that performance improves in approximately two out of three programs (Heneman, Ledford, \& Gresham, 2000). Gibson (1995) reported on a study by Carla O'Dell and Jerry McAdams (sponsored by World at Work and conducted by the Consortium for Alternative Reward Strategies), which suggested that the average net return 
However, despite the breadth and sophistication of topics being examined in research related to pay-forperformance, the crucially important issue of managers' approach to implementation has not received much attention. on money invested in pay-for-performance programs was an impressive $134 \%$. Surveys of 500 companies reported in the Economist ("Business: Pay Purview," 1998) indicated that those actively using pay-for-performance programs showed twice the shareholder returns as those who were not actively using these programs.

Proponents of pay-for-performance assert that traditional compensation systems can be detrimental to efforts to make an organization less hierarchical and more competitive, focused, adaptable, and collaborative (Baker, 1993). For example, traditional pay systems may experience the following problems: pay becomes an entitlement, benefits are given for tenure, base pay is a function of levels and not performance, merit increases do not differentiate performance sufficiently, and even executive bonuses become an entitlement.

Recent research has examined a variety of ways in which pay-for-performance systems impact individuals, groups, and organizations (Stajkovic \& Luthans, 2001). There has been a growing interest in group pay-forperformance systems and the conditions under which they are most effective (GomezMejia, Welbourne, \& Wiseman, 2000; Hollensbe \& Guthrie, 2000). Scholars are also looking not just at motivation, but also at the broader impact of pay-for-performance systems, such as how they affect organizational learning (Arthur \& Aiman-Smith, 2001), the type of employees who self-select into and out of the organization (Banker, Lee, Potter, \& Srinivasan, 2001), and the managerial turnover within the organization (Bloom \& Michel, 2002). In addition, gender differences and their impact on pay satisfaction (Graham \& Welbourne, 1999) have been identified, as have the consequences associated with satisfaction with pay systems (Miceli \& Mulvey, 2000). The impact of pay dispersion has also been a topic of growing interest (Bloom, 1999; Bloom \& Michel, 2002; Shaw, Gupta \& Delery, 2002). Furthermore, some attention has been given to particular professions, such as accounting, and the distinctive impact that pay-for-performance systems can have on different professions (Bonner \& Sprinkle, 2002).
However, despite the breadth and sophistication of topics being examined in research related to pay-for-performance, the crucially important issue of managers' approach to implementation has not received much attention. Pfeffer (1998) argues that there are significant potential problems with implementing pay-for-performance programs. For example, pay-for-performance systems can have a destructive effect on intrinsic motivation, self-esteem, teamwork, and creativity (Amabile, 1988; Beer \& Katz, 2003; Deci \& Ryan, 1985; Kohn, 1993; Meyer, 1975; Shaw et al., 2002). Furthermore, other scholars have argued that the real problem is that incentives work too well. Specifically, they motivate employees to focus excessively on doing what they need to do to gain rewards, sometimes at the expense of doing other things that would help the organization.

Pay-for-performance advocates respond that intelligent design of programs is essential to avoid these pitfalls. However, intelligent design alone is insufficient to assure the success of such programs. As Pfeffer and Sutton (2001) note, persistent gaps exist between what managers know (the concepts they can articulate) and what they can actually do. Thus, intelligent design must accompany effective implementation over time in order for pay systems to run effectively. In particular, two significant barriers must be overcome: barriers associated with linking performance to effort, and with linking pay to performance. In addition, these must be overcome in a way that is perceived as fair and equitable by management and employees alike.

Potential barriers to linking performance to effort include difficulties in measuring performance; factors outside the control of individuals and groups being paid for that performance; and that managers and peers are uncomfortable with rating employees differently. Potential barriers to linking pay to performance include the following: employees can come to rely on the additional compensation; employees are biased toward overestimating their own contribution; corporate budgets for bonuses often limit payout; and managers can lose commitment to the pay system if it pays out more than anticipated due to problems in payout standards and if 
there are changes in performance standards due to changes in technology and organizational arrangements and unanticipated learning curves. It is changing circumstances that make it difficult for managers to sustain links between pay and performance in a way that will avoid perceptions of unfairness and inequity. Such perceptions can undermine the perceived link between pay and performance so important to sustain its motivational power.

Despite the importance of understanding implementation in order to overcome these and other barriers, little research has studied implementation (Fay, Thompson, \& Knight, 2001). In a broad review of the theory and evidence on compensation practices, Gerhart and Rynes (2003) detected a number of significant disparities between what is important to know about compensation and what is being researched. In addition to the lack of attention to implementation, the study of managerial decision making related to pay systems has also been neglected. More specifically, Gerhart and Rynes (2003) note that pay practices vary widely and are not simply dictated by market forces and the environment. Instead, managers play an active role in determining whether to initiate, retain, or modify a system of pay-for-performance and what type of system to use. However, very little academic research has investigated how managers make these decisions.

The focus of this article is on the experience of managers in one company in implementing pay-for-performance and how they made sense of and made decisions about their pay-for-performance initiatives. In addition, one other neglected area of research we will deal with in this article has to do with how an organization's particular or distinctive culture might affect its management's ability to effectively implement a particular pay-for-performance system. In other words, rather than assuming that there are universal best practices for pay-for-performance, it may be that what is effective for a particular organization depends on some unique aspects of its culture, and one must, therefore, be cautious in generalizing from one organization to another, even within the same industry (Gerhart \& Rynes, 2003). More specifically, Gerhart (2001, p. 235) has argued that a pay-for-performance program might be more easily implemented in an organization that has distinctive characteristics, such as the following: "(1) the culture discourages opportunism, (2) top management reinforces this culture by its example, and (3) employees have long-term careers or professions in which their reputation is a valuable commodity."

Our goal in this article is to provide case data and share insights that inform these neglected research areas. Specifically, we examine managerial decision making and sense making in the area of designing and implementing five pay-for-performance systems in a high-commitment culture-HewlettPackard (HP). This study does not attempt to assess the efficacy of pay-for-performance programs, though the initial experience with pay-for-performance indicated it had a positive impact on motivation and performance.

A case-writing visit to Hewlett-Packard in the mid-1990s presented an unusual opportunity to study the managerial experience of implementing pay-for-performance programs. In the early 1990s, local HewlettPackard managers at thirteen different sites established pay-for-performance initiatives to improve their businesses. HewlettPackard provided us with the opportunity to review their documents and to interview the managers who sponsored the pay programs. We report here on five of the thirteen payfor-performance initiatives that we researched. The fact that the events reported here occurred in the early 1990s does not take away from the findings and insights since they represent dilemmas managers would face today in implementing pay-forperformance in a high-commitment culture such as the one HP had during the period in which the pay initiatives took place (it is widely acknowledged that since $1999 \mathrm{HP}$ has moved away from its traditional high-commitment culture).

This novel research opportunity offered several methodological advantages compared to many previous studies. Specifically, many other studies relied on only one or a very limited number of cases, which makes generalizations difficult. Previous studies often covered
... the study of managerial decision making related to pay systems has also been neglected. 
In order to give fair treatment to the topic of implementation of pay-forperformance, knowledge about the context in which the pay system is being implemented is necessary. such short time frames that the long-term efficacy of the programs was difficult to assess (Luthans \& Stajkovic, 1999). Interviewing local managers, as we did, is also not a typical characteristic of previous studies. Yet, interviews were essential for us to accomplish our goal of better understanding how the managers were making decisions about the introduction of a pay-for-performance system and later how they made sense of various performance and human outcomes and drew conclusions with regard to the success or failure of their pay design.

In order to give fair treatment to the topic of implementation of pay-for-performance, knowledge about the context in which the pay system is being implemented is necessary. That context, the company culture, the measurement and performance management systems in place-the motivation of managers to implement pay-for-performance and their effectiveness as managers - can have an important effect on the success or failure of the pay-for-performance system. We had a lot of information on this context from two cases on HP that had been written by one of the authors in 1982 and again in 1995 (Beer \& Rogers, 1995; Beer \& von Werssowetz, 1982). Indeed, the HewlettPackard cases on which we report here had in place many of the conditions that should lead to success. First, they were the initiatives of local management; thus, local management had a very high level of commitment to their successful implementation. In addition, these initiatives had the approval and full support of higher management. Resources such as consultants were also made available to support these programs. Furthermore, with a reputation as a high-commitment company (Beer \& Rogers, 1995; Collins \& Porras, 1994) in which trust between management and employees is strong and in which communication is good, we would expect HP to have an advantage in implementing these programs. In fact, Gerhart (2001) specifically hypothesized that pay-forperformance systems introduced in organizations with cultural attributes such as those at HP would experience fewer problems than those introduced in other organizations. Similarly, lack of trust (Pearce, Stevenson \&
Perry, 1985) and poor communication (Hammer, 1975) has been cited as the cause for the failure of other programs. Thus, this investigation enables a preliminary test of the proposition that high-commitment cultures make it easier to implement pay-for-performance systems.

Furthermore, local managers had significant autonomy and the freedom to continue or discontinue their pay-for-performance programs, depending on how they assessed the costs and benefits. They were not constrained or pressured by outside forces to do either. Therefore, we were able to study not only the challenges these managers encountered in implementing the programs but also the decision-making processes that they used in responding to these challenges over time, as well as their attribution of benefits and costs that guided these decisions. These conditions provided an unusual opportunity to examine the natural evolution of the decisionmaking and sense-making processes in which these managers engaged as they initiated and then implemented these pay programs in a high-commitment company.

Along with these advantages, we should also acknowledge that our data set has some significant limitations. The fact that these initiatives emerged naturally meant that this research is not a randomized experimental design with control groups, despite the fact that Hewlett-Packard's corporate human resource executives thought of them as "experiments." The "experiments" emerged spontaneously as a result of what was going on with local management. We therefore refer to them in this article as "programs" or "initiatives" rather than "experiments." Given that these initiatives were conceived and implemented by practicing managers, they also lacked some of the measures of satisfaction and other variables that could have been of interest to researchers (Sturman \& Short, 2000).

\section{Setting and Method}

Beginning in the early 1990s, HP authorized a diverse set of 13 different alternative pay programs (Table I). Most of these in- 
volved team- and skill-based pay systems; some involved gain sharing and some cash incentives or bonuses. Half the sites were outside the United States and were spread across five countries. The workers included were mostly involved in various kinds of blue-collar work at the production level, with the exception of one group of engineers. All programs were initiated at the request of local divisional management. In each instance, local management felt it needed to use pay-for-performance as an additional inducement either to achieve particular goals, to reinforce learning and/or team behavior in semi-autonomous teams, and/or to compensate for an increase in span of control due to de-layering.

\section{The Company}

These initiatives must be understood in the context of HP's corporate human resource policies and culture at the time. Initiated by its founders, numerous highly consistent and mutually reinforcing policies and practices have developed over HP's 50-year history (Beer \& Rogers, 1995; Beer \& von Werssowetz, 1982). These include the following: decentralized business units; strong commitment to management by objectives; participative management and delegation of responsibility to the lowest level; extensive communication, such as open-door policies and "management by walking around"; recruitment and hiring practices that screen for interpersonal skills, not just technical competencies; and a career system based on internal promotion and cross-functional and divisional movement.

HP's pay systems included the following at the time of these initiatives: merit pay based on ratings by supervisor (for exempt and nonexempt employees) and performance ranking of employees (exempt employees); a profit-sharing system for all employees that pays out the same percent of salary, regardless of level; no executive bonus system, though total executive compensation was comparable with industry standards; stock options for employees at all levels according to contribution; and incentives used in the sales organization (team and individual).
Research Method

HP's corporate human resource department tracked these programs and learned that all were discontinued within approximately three years. An internal study was commissioned to understand the reasons why each was discontinued so that implications for the future could be drawn. Their methods were interviews, examination of production data, and employee surveys. We reviewed HP documents. We also conducted interviews at five U.S. sites to gather additional data. The interview protocol involved an introduction in which we explained that we were doing follow-up research on their payfor-performance initiatives, and we assured them that what they said would be confidential. We then asked them to describe the pay-for-performance program they had introduced. Then we probed further to learn the managers' perspectives on these programs: what they had hoped to achieve, the challenges they faced in implementing the pay program, their response to the challenges, their own calculus of the cost and benefits of using pay programs as an active management tool, and the reasoning behind their eventual decision as to whether to continue the program. These interviews provided us with an opportunity to deepen our understanding and to validate HP's own conclusions.

Given space limitations, we provide brief descriptions and findings from the five sites in which we conducted interviews. The results at these sites are illustrative of results for HP's larger data set of 13 initiatives, but we confine our later discussion to the findings from these five pay initiatives.

\section{Five Case Examples}

\section{Case 1: San Diego Site}

Description. In an effort to support a transition to self-managed teams and encourage a focus on team rather than individual performance, the San Diego site initiated team pay-for-performance (TPP). Previously, responsibility for implementing HP's

\section{... local management felt it needed to use pay-for- performance as an additional inducement either to achieve par- ticular goals, to reinforce learning and/or team behavior in semi- autonomous teams, and/or to compensate for an increase in span of control due to de-layering.}


During the first six months, team members liked the TPP program and significantly outperformed the performance goals set at the beginning of the experiment... merit-based pay philosophy and for managing the development of employees was given to individual managers who would divide workgroup objectives into individual assignments and then monitor individual contributions. Under the new self-managingteams structure, a layer of supervision had been removed, and managers had wider spans of control and less managerlsubordinate interaction. Teams themselves divided up the work and were managed to a set of business objectives. Consequently, managers were not as well positioned to make merit-increase decisions or to manage the development of individual employees. Therefore, management put together a TPP plan to focus employees on team performance and to encourage them to manage their own development and acquire the broader set of skills that would be required by workteam responsibilities.

Team pay-for-performance was established to motivate achievement of specific workteam goals, such as team-process improvement, production, and quality goals. The team-based pay for achieving certain goals was added incrementally to base pay. There was no "takeaway" for failing to meet team goals. Three levels of team performance were possible within the pay structure. Ninety percent of the teams were expected to achieve Level I performance and thus receive a payout. Fifty percent were expected to reach Level II performance, and 10-15\% Level III performance, the highest level. For achieving Level III performance, for example, members of a particular work team would receive between $\$ 150-\$ 200$ additional pay at the end of the following month. Teams also had production coaches to assist them.

San Diego's new pay package also included a skill-based pay system called payfor-contribution (PFC). Instead of the typical merit system, employees would advance from a starting rate by demonstrating competence to perform additional sets of tasks within the team. The system was intended to motivate employees to learn new skills on an ongoing basis. Possession of a new skills set was measured and certified by "subject matter experts." The rationale was to create a continuously learning workforce capable of adapting to new situations.

Results. During the first six months, team members liked the TPP program and significantly outperformed the performance goals set at the beginning of the experiment, with a majority of the teams reaching Level II and III. However, because the TPP program paid out more than expected, management concluded that they had set the performance standards too low and decided to adjust them. This effort was met with great resistance from team members, who complained bitterly. They had built a lifestyle around the higher monthly pay they had come to expect, and now saw the program as taking something away. Managers also concluded that workers' attention was now focused on their pay instead of their work.

Another drawback of pay-for-performance that managers saw had to do with factors outside of the teams' control that affected team performance. For example, delays in shipment of parts or a mechanical breakdown in the assembly line prevented teams from building the units they needed to meet their goals for that month. This caused serious dissatisfaction with the pay system. Team members felt as though they had very little control over their performance.

Furthermore, high-performing teams often refused to admit anyone to their team who they thought might be below their level of competence. This resulted in selfreinforcing positive and negative spirals in team performance. Some teams had many top performers, while others stagnated with low performers who needed further training. Furthermore, barriers to employee mobility between teams reduced the capacity of the organization to transfer learning from one team to another, a major barrier in a dynamic environment.

Regarding the skill-based PFC pay system, management reported that the majority of employees disliked this system. They did not like the additional pressure of taking tests to increase their pay, some in how to read and write and do math. Because they were afraid it wouldn't leave them enough time to study and test for new work skills, employees would 
often refuse new job assignments. Moreover, many of the newly acquired skills were not used on the job. Furthermore, at the beginning of the program, employees had to demonstrate proficiency on skills required in their current job to maintain their skill classification. If they failed, the system called for them to drop to a lower classification and pay level. Managers found it difficult to do this, however. These constituted takeaways from expected levels of pay that had been established in the minds of employees.

Local site managers concluded that a team structure together with training would have provided the same benefits as the team structure combined with team- and skillbased pay, but without the additional effort, money, and communications demanded by the team-based pay system.

Managers also concluded that the pay system did not motivate employees to work harder or learn, though it did stimulate them to better understand relevant performance metrics, the manufacturing system as a whole, and its broader goals. This improved understanding may have been used by employees to define their own interests rather than the broader interests of the organization as a whole when TPP stopped paying off.

One of the largest of the San Diego site divisions dropped the pay program after about a year. Managers were tired of having to constantly reengineer the pay system to overcome its numerous problems. Surveys indicated that employees preferred to switch back to HP's standard pay structure. When management of that division announced they would drop the pay program, employees threw a party to show their gratitude.

The rest of the site eventually dropped the program as well, due to a major manufacturing reorganization. The divisions found that team-based pay made it extremely difficult to maintain consistency in the pay system across the whole site.

\section{Case 2: Boise Printer Formatter Shop}

Description. The Boise situation was similar to San Diego; they had introduced self-managed teams, and management wanted to implement a complementary team and individual performance incentive plan. The traditional HP merit pay system was replaced with a skillbased pay system. Within a skill level, pay could be increased variably depending on individual and team performance. If a team was among the highest-performing teams for a particular month, it was awarded a bonus. Those who were evaluated as performing above average were allowed to pursue development and advancement to the next skill level with resultant higher pay. Because these teams were intended to be self-managing, the evaluations were to come from peers and management. Those with performance problems could not pursue new training opportunities until their performance was corrected. This system was designed to provide additional pay, not to take any pay away when team performance lagged.

Results. The results were very much like those at San Diego. It was difficult to establish realistic performance goals. After some months, teams received much more contingent pay than had been expected. Management at this site also found it very difficult to reset goals once they were established. Here, too, teams became very selective about who they wanted on their team. External factors outside of the team's control also affected goal accomplishment and irritated many of the employees.

Peer evaluation of individual performance, also part of the system, was difficult to implement. Team members had a very difficult time judging the work of their respective team members. Tempers flared after employees received negative feedback. Consistent with attribution theory, negative evaluations were attributed to a bad evaluation system and teammates that were not objective. This, of course, led to further problems within teams.

Like San Diego, the pay program was dropped. Long-term results initially hoped for never materialized. Management came to believe that employees were too focused on pay and insufficiently focused on the task.

\section{Case 3: PRCO Loveland}

Description. PRCO is a printed circuit fabrication shop that was slow in reaching its targets.
Managers were tired of having to constantly reengineer the pay system to overcome its numerous problems. 
... managers

felt that a more effective approach would have been to work on coaching employees in how to make manufacturing process improvements.
During one quarter, the fabrication shop was behind schedule and wanted to reach at least $95 \%$ of its target. With a month left, management offered a $\$ 250$ cash bonus to all of its employees if they reached the goal.

Results. The shop didn't reach its goal and the bonus was never paid out. Managers reported that employees were not angry when the bonus did not materialize. On the positive side, managers reported that the bonus did highlight their serious intention to reach the production target. On the negative side, some employees felt insulted by the fact that the company tried to "bribe" them to reach a goal that they were already motivated to reach. In the final analysis, managers felt that a more effective approach would have been to work on coaching employees in how to make manufacturing process improvements.

\section{Case 4: Colorado Memory Systems}

Description. Colorado Memory Systems (CMS), which was acquired by HP, had not previously had a profit-sharing system. Prior to being acquired, management thought they would take the company public. Employees were told that they would have a chance to share in the company's success through stock-purchasing plans.

When the company was acquired by HP, the stock-purchasing plan did not materialize. CMS management opted to institute HP's corporate profit-sharing program to engender a feeling that they were becoming a part of the larger HP organization. However, management did not feel they could afford to pay employees at HP levels. Thus, they instituted a local gain-sharing program that they hoped would augment CMS's base salary and provide employees with total compensation that matched or exceeded HP's total compensation package.

The local gain-sharing program was installed by management because they believed it would increase the following desired behaviors: individual initiative and responsibility; willingness to learn; adaptiveness; teaming and collaboration; hustle; willingness to confront conflict; and focus and attentiveness. Managers believed that increas- ing these behaviors would translate into increased financial success for the company and help to close the "pay gap" between CMS and HP. Management planned to pay out bonuses quarterly based on attainment of certain levels of operating profit.

Results. Management reported that the program had the following positive effects: increased visibility between departments, the effective use of cross-functional teams to achieve goals, a heightened awareness of business fundamentals and financials, clearly defined and communicated quarterly objectives, and a high level of uniform companywide focus.

However, a number of problems soon emerged. For example, many employees wanted their compensation program to be the same as other HP employees. Employees also perceived the program to be promoting short-term behavior.

In addition, the gain-sharing program intended that employees be rewarded on the success of CMS. After integration into HP, it became difficult to determine whether CMS's performance was attributable to its own employees' efforts or to contributions made by other HP departments and employees. Finally, for the program to pay out enough to close the gap with the HP pay scale, CMS managers judged they needed to pay out at least five out of six times (payouts were every two months) and average at least $10 \%$ of base salary. The program only paid out four out of six times and averaged $6.13 \%$ of base pay. Employees began to question the program, and its credibility was damaged. Due to these and other concerns, management concluded that the benefits of the program did not outweigh the costs.

\section{Case 5: The Workstations Group}

Description. HP was having considerable trouble completing their new high-speed UNIX-based workstations in the early 1990s. Because speed to market is so important in the high-technology arena, management made the introduction of this product a very high priority. Local management wanted to complete the project early, with high quality 
and with all the standard support services ready and trained. They, therefore, attempted to motivate employees to work more efficiently and effectively by implementing an experiment in pay.

The pay program introduced offered two different bonus packages, one for managers and one for engineers, to be paid at the completion of the project (if accomplished by the target date). Because management realized that the decisions made by managers would be vital to success, they offered a cash and stock program for managers $(10 \%$ of salary stock grant and $5 \%$ of salary in cash). Stock awards were to be given six months after completion of the project to ensure quality of product and customer service. Engineers were to receive cash (between $5-7 \%$ of salary). The pay program was intended to motivate effective completion of the project. There was no intention to continue it. The reward amounts depended on a nomination and approval process that determined individual levels of contribution.

Results. The project was completed six months ahead of the target date. While some in the organization saw this as a success story for pay-for-performance, others were quick to point out that the pay program did nothing more than communicate the utmost importance management was placing on this project. Many people, including Pete Peterson, vice president in charge of personnel, believed that the perception of high priority was the most important motivating factor leading to the early completion of the workstation. A local personnel manager validated this view independently. She referred to the pay system as the "great catalyst" in the project. The fact that HP utilized an incentive program that had such high visibility showed, she felt, that the company was willing to try something new to get the workstation finished. That was motivating in itself.

An HP survey showed that $70 \%$ of the employees felt they would have worked just as hard on the project without the incentive program. But interestingly enough, $60 \%$ of the employees surveyed recommended that incentive programs be used with other projects at HP.

\section{Summary of Hewlett-Packard Conclusions}

Hewlett-Packard corporate executives examined the results of these five cases as well as those of the additional eight programs that we do not report on here (see Table I). Their goal was to learn from these "experiments" and use this data in making decisions as to whether to encourage broader use of payfor-performance at Hewlett-Packard. The additional eight programs had similar outcomes to those reported here. The local managers who enthusiastically initiated these pay-for-performance programs ran into difficulties in implementation and maintenance and were ready to abandon them so they could allocate their efforts elsewhere. In the calculation of local management, the benefits of most of these programs did not outweigh their costs. In other cases, such as the workstation group described in case 5, though implemented without difficulties, local management and the corporate compensation department were not convinced that the alternative pay program could be credited with performance outcomes. Specifically, they were not clear whether the outcomes were motivated by the rewards themselves or whether they were motivated by the implicit message that Hewlett-Packard's introduction of the reward system was communicating the importance of the goals.

Based on the experiences reported by management at these 13 sites, HewlettPackard executives decided to discontinue experimenting with the alternative pay-forperformance programs. The reasoning and conclusions that the local managers shared in our interviews at the five sites were consistent with the reasoning and conclusions shared in Hewlett-Packard's "White Paper." Below are some of final conclusions from this report (White Paper, 1994):

1. "Team-based work environments appear to be producing increasing business results."

2. "Alternative pay systems have not proven necessary to produce positive results."
The local managers who enthusiastically initiated these pay-forperformance programs ran into difficulties in implementation and maintenance and were ready to abandon them so they could allocate their efforts elsewhere. 
TABLE I Locations, Programs Elements, and Final Status

Locations (Date Approved)

Workstations Group (7/90)

Puerto Rico (10/90)

San Diego Site (2/91)

$\operatorname{NCMO}(2 / 91)$

Eastern Sales

Parkridge, NJ (12/91)

Boise Printer Division (12/91)

Vancouver Division and ICD (9/92)

Colorado Memory Systems (3/93)

Medical Products Group (7/93)

PRCO Loveland (7/93)

Belgium (10/93)

Italy Sales (10/93)
Program Elements

- Cash

- Incentive awards

- Skill-based pay (with payfor-performance)

- Team bonus

- Skill-based pay (no payfor-performance, 9/93)

Team bonus $(6 / 92)$

- Gain sharing

- Division profit sharing (gain sharing)

- Modified skill-based pay (with pay-for-performance)

- Transitional reward and incentive plan

- Skill-based pay (no pay-forperformance, 2/93)

- Team bonus (2/93)

- Bonus pay for production operators and supervisors

- Gain sharing with pay at risk

- Team recognition and reward

- Bonus program to increase yield to $95 \%$ for Q4 FY93

- Base pay indexed with merit pay as bonus

- Freeze base pay with bonus for performance
Final Status

Implemented; Completed 1992

Discontinued

Discontinued

Cancelled by entity management due to organization change LID (5/91)

Cancelled by entity management due to division reorganization

Program implemented but cancelled due to reorganization (part of organization moved to Roseville)

Discontinued

Discontinued

Program stopped due to reorganization 9/94

Discontinued

Discontinued

Not pursued at country's request

Discontinued
3. "HP's current pay system and other tools are sufficient to support the work team environment."

4. "Even though HP has gained valuable organizational learning from alternative pay experiments, the high resource commitment necessary to design and implement pay system changes, and the limited return so far, indicates that HP does not need additional experiments unless they are markedly different."

\section{Discussion}

The five cases we researched provide a number of insights into the dynamics of managerial decision making in implementing pay-for-performance in a high-commitment company. As stated by Gerhart and Rynes (2003), pay programs are not simply determined by forces in the external environment. Instead, managers play a significant role in the adoption, modification, or discontinuation of pay-for-performance 
programs. However, current research tells us little about how managers actually make such decisions.

To understand the managerial decision making at Hewlett-Packard, we should first examine how managers were conceptualizing their work with pay-for-performance. We observed that managerial thinking was driven foremost by a pragmatic commitment to finding ways of improving performance. They were not driven primarily by a deep philosophical commitment to pay-for-performance or a desire to apply their newly acquired knowledge about pay-for-performance. Their goal was to improve performance. They conceptualized pay-for-performance as an underutilized tool among a variety of tools in their managerial tool kit they hoped could help them solve problems they were facing. They hypothesized that implementing payfor-performance programs would be a costeffective way of boosting results. When their pay initiatives had unintended consequences, the managers retained their pragmatic focus on improving performance and concluded that they could gain more leverage through alternative managerial tools such as good supervision, clear goals, coaching, training, and so forth. This decision does not imply that managers believed that pay did not motivate or that it could not be used effectively in other settings. It does imply that management saw their effort/benefit ratio as more favorable if they focused on the fundamentals of management that had served Hewlett-Packard well in the past.

One of the most prevalent and striking themes in managerial decision-making in these cases is the size of the gap between managers' initial expectations and the subsequent realities. Managers made overly optimistic assumptions about how much time would be required and how difficult it would be to administer and make adjustments in these pay programs. Managers were also overly optimistic about the benefits that would be achieved.

The biggest problem proved to be setting performance standards that would strike the right balance between paying out enough to make incentives motivational without paying out too much. The need to make adjustments or renegotiate standards caused significant problems. Presumably, the unusually high levels of trust and communication at HP should have given them an advantage in working out such problems. However, making adjustments produced major conflict and lost trust, despite the superior levels of communication, trust, and commitment at HP.

This finding runs counter to the hypothesis that a company and culture like HewlettPackard's should make implementation of pay-for-performance easier. However, it is supported by findings that executives in high team-oriented cultures, when compared with executives who perceived their cultures as less team-oriented, observed more rather than fewer unintended negative outcomes (damage to teamwork and gaming, etc.) as a result of executive incentive systems employed by their firm (Beer \& Katz, 2003). To understand this counterintuitive finding, we draw on prospect theory (Kahneman \& Tversky, 1979), which suggests that people tend to be loss-averse and have a peculiarly strong reaction to the potential for loss. At the outset, managers and workers were each focused on the prospects for gain. However, employees came to rely on the extra money and perceived changes in terms of loss or taking away something positive that they had come to expect. Likewise, as workers reacted emotionally to what they perceived as loss, managers also became sensitized to what they had to lose-which were the benefits of the trust the corporation had built over time. So a high-commitment culture may be a double-edged sword. On one hand, greater trust and a better relationship among management and workers, could increase the initial acceptance of and support for new pay initiatives. On the other hand, when complications threaten to undo the benefits of previous managerial work, managers and workers, who have invested more in building trust and have more to lose, may be quicker to reject programs that put at risk the relationships they have invested significant time into cultivating.

The turbulence of the technology industry and the need to adapt continually took its toll on these programs. Workers' aversion to fluctuating payouts, particularly reductions in payout or no payout at all, did not mesh well with the rapid pace of
When their pay initiatives had unintended consequences, the managers retained their pragmatic focus on improving performance and concluded that they could gain more leverage through alternative managerial tools such as good supervision, clear goals, coaching, training, and so forth. 
... the more rapid the pace of change, the more difficult and timeconsuming pay-forperformance programs are likely to be to design and maintain. change in the technology industry. The efforts by management to change payout standards in response to new technology or simply unanticipated performance improvements and payouts also threatened trust and commitment of employees. This finding is consistent with previous experience with and research on incentive compensation for production employees. Many of the piece-rate systems that were very popular in the $1950 \mathrm{~s}$ and 1960s disappeared due to similar reactions from employees. Inflexibility on the part of workers can be particularly problematic in the technology industry, where firms need to innovate continually and improve efficiency just to stay competitive. Two of the pay experiments were one-time events, but four out of the eleven programs that, ideally, would have been ongoing were disrupted by reorganizations or other organizational changes. Similarly, disruptions in other areas of the company (outside of the control of the organizational units experimenting with pay) interfered with employees' ability to achieve performance objectives and rewards. This caused major frustrations for the workers. It suggests the importance of the context; in particular, the more rapid the pace of change, the more difficult and time-consuming pay-for-performance programs are likely to be to design and maintain. Future consideration should be given to the rate of change in the environment and its impact on such systems, particularly for lowerlevel employees whose compensation is lower than that of managers. This may be of particular concern, given the general rate of acceleration in competitive forces and the need to adjust to them.

The fact that managers had misestimated the potential difficulties and the need to make adjustments in payout standards meant that they were somewhat limited in their ability to communicate clearly about what workers should expect. Nonetheless, in theory, either group could have initiated more explicit sharing of expectations. Both management and employees had hopes and expectations of the pay system. Management hoped to obtain some kind of cost savings or productivity gains while employees hoped for additional pay. Both workers and managers appear to have been overly optimistic about their ability to achieve benefits from the pay systems (Taylor \& Brown, 1988), and neither group was particularly explicit in communicating their expectations to the other. It would have been interesting to see what the reaction would have been if both sides had communicated their expectations clearly. Perhaps if their expectations had been voiced and explored, they would have been able to recognize potentially incompatible expectations and could have made more-informed decisions as to how to proceed.

All of this suggests that there is an implicit negotiation going on anytime a payfor-performance system is introduced. Both parties accept the new pay practice based on unstated and undiscussed expectations. When circumstances change, a "negotiation" about how to alter the pay system to meet these expectations is very difficult. The Hewlett-Packard case suggests that such an explicit ongoing process of discussion and negotiation during the life of the pay system may be necessary to assure a longer life for pay systems than that typically experienced by corporations. It is interesting that management at HP, a firm whose philosophy and values would have made a dialogue about pay-system redesign more possible than in most firms, did not see this as an option. We suspect that this may have something to do with assumptions most managers make about how much participation is possible or advisable about pay systems. The case of Sedalia Engine (disguised name), a high-commitment manufacturing plant, is instructive in this regard (Beer \& Spector, 1982). Facing discontent from employees with pay, the plant manager decided to convene a task force of employees, against the advice of higher management, to make recommendations about how the pay system should be redesigned. The view of higher management in that case is clearly the dominant view of most managers. However, the positive outcome at Sedalia (the recommendations were not self-serving and resulted in a practical solution to which employees were 
committed) and research by Lawler \& Hackman (1969) suggests that participation of employees in pay-system redesign may be possible.

\section{Conclusion}

That Hewlett-Packard managers abandoned the pay-for-performance programs they initiated with great hope tells us more about how managers were conceptualizing their options for influencing employees than it does about pay-for-performance programs per se. We do not draw the conclusion that pay-for-performance plans do not motivate. Indeed, the initial performance improvements obtained suggest that pay-for-performance did motivate behavior desired by management.

The case data presented here does suggest that pay-for-performance systems present implementation problems that may be underexamined by researchers and insufficiently acknowledged by practitioners. Part of the problem stems from a fundamental human tendency, to which managers are also subject, to be unrealistically optimistic about what can be accomplished by a management intervention (Rigby, 2001; Taylor \& Brown, 1988). Another aspect of these unrealistic assumptions may be attributable to the inherent complications in designing and maintaining effective pay-for-performance programs, particularly in the rapidly changing business circumstances that face many companies today. In these circumstances, the barriers to linking performance with effort and the barriers to linking pay to performance, discussed earlier, are significant and were not apparent to managers at the time they launched the pay programs. Managers may also have been unaware that, unlike other interventions such as training, shortcomings in the design or maintenance of pay-for-performance programs can actually cause significant problems such as bitter feelings and damage to important relationships.

The implementation costs and risks of pay-for-performance systems appear to be higher in high-commitment cultures like HP where trust and employee commitment is perceived by managers to be crucial to longterm success, though more research is needed before conclusions from this case can be generalized. Managers at HP probably weighed the dissatisfaction of employees with incentive programs or their attribution that a one-time bonus "was a bribe" differently than managers in firms without a highcommitment culture. Ironically, HewlettPackard's distinctive culture seems to have had an unexpected disadvantage, one that runs counter to prediction in the literature (Gerhart, 2001, p. 235). This may suggest that the conclusions of this study do not apply to low-commitment firms. An alternative conclusion is that monetary incentives in a fast-changing environment may undermine the capacity of a firm to build trust and commitment unless the process of introduction incorporates an honest discussion of mutual expectations.

The implications for practice we draw from these cases is that managers might best approach the introduction of pay-forperformance systems as a process of "negotiation" with employees if they are to avoid the unintended consequences we observed at HP. They might state clearly their expectations for the program and ask employees (through a representative task force) to clarify theirs. Both sets of expectations would ideally inform the design of the pay program and the process for reexamining and redesigning the pay program should expectations of either side not be met. There is some evidence that this sort of participation works (Lawler \& Hackman, 1969) but considerably more action research in a variety of organizational cultures is needed to test this proposition and the contingent situations in which it might apply. Clearly, management's philosophy with regard to employee participation and power sharing will influence its propensity to employ the process of participation and negotiation we are suggesting.

\section{Stress-Testing the Conclusions}

All research, particularly a case study like this one, is subject to a variety of interpretations. Are our findings an artifact of circumstances
... pay-forperformance systems present implementation problems that may be underexamined by researchers and insufficiently acknowledged by practitioners. 
Is it possible

that the

managers in

our case were

wrong when

they abandoned

the pay-for-

performance

system due

to concerns

about employee

trust and

commitment? that may not have been explicated in the case itself? We have discussed the high-commitment culture of HP as an important factor in the decision to abandon pay-for-performance. But was preserving the culture a mistake? Below we will evaluate this question and other situational factors that one could argue undercut our interpretation of the HP cases we discussed above.

Hewlett-Packard had exemplary financial performance for nearly six decades (Beer \& Rogers, 1995; Collins \& Porras, 1994). However, the company's performance suffered in the late 1990s compared to competitors (Beer \& Weber, 2003). In response, the board of directors recruited Carly Fiorina, a senior executive from Lucent, to lead the company. She immediately set about changing the culture through a variety of interventions, including the introduction of an extensive pay-for-performance incentive system (stock options and bonus systems) for a substantial number of senior executives (Beer \& Weber, 2003). As we discussed above, HP had never used pay-for-performance systems as a primary tool for motivation and was one of the few companies that did not have executive bonus systems. Is it possible that the managers in our case were wrong when they abandoned the pay-for-performance system due to concerns about employee trust and commitment? Could it be that they missed a crucial opportunity to change HP's culture in their organizational unit when they did not persist with the pay-for-performance pay system they had introduced? Such changes are disruptive as was evident when Fiorina's efforts to change the culture roused strong negative employee reactions (Beer \& Weber, 2003; Burrows, 2003). Perhaps they should have ignored the reaction of employees and recognized that to change HP's performance a countercultural pay-for-performance system was needed? Indeed, this is precisely the argument for pay-for-performance its advocates espouse. It is a way to change entitlement cultures and improve financial performance dramatically (Baker, 1993). We do not think this interpretation of events at $\mathrm{HP}$ is warranted given 1) the performance of the company since Fiorina introduced the incentive system and changed HP's culture and 2) the evidence about the performance of high-commitment cultures that typically do not rely on individual and group pay-for-performance systems to motivate instrumentally, though they use money to recognize performance.

Hewlett-Packard's performance since Carly Fiorina introduced pay-for-performance at the executive level has been less than stellar (Beer \& Weber, 2003). The company has not achieved many of the financial results she promised and is continuing to lose market share to Dell. If HP's financial performance in the 1990s is used to argue that the pay-for-performance system, abandoned by the managers in our case, was needed to change the culture and improve lagging performance, then it is equally valid to question the value of pay-for-performance and the new culture introduced by Fiorina in 1999 given the company's performance between 1999 and 2003.

It is our view that financial performance, except over a very long time period (decades), is not a good criterion for evaluating pay-for-performance systems. It is a function of so many factors that to attribute this outcome to pay-for-performance is a vast oversimplification. Behavioral and intermediate operating outcomes seem much more appropriate. We argue that HP's financial performance problems lay in poor strategy and in their inability to redesign the corporate organization to enable the integration of HP's many products into solutions for customers, something that IBM has been able to do. There is much evidence to indicate that these problems were tied to political problems triggered by the CEO succession process at the top that no incentive system would have solved (Beer \& Weber, 2003).

One could also argue that HP managers had their eyes on the wrong measure for judging whether the pay system was a success. Pay-for-performance advocates argue that clear and explicit performance goals must be present for a pay-for-performance system to work effectively and these performance goals should be the criterion 
for deciding whether a pay system is working. Instead of attending to employee concerns and loss of trust, the managers at HP should have kept their eyes on operating results and ignored employee attitudes. After all the pay-for-performance system had boosted productivity in the months after its introduction. This argument seems to us to ignore decades of evidence that trust and commitment are essential to the capacity of organizations to outperform their competitors. Can increasing distrust and reducing commitment ever improve performance?

High commitment can only be created if employees develop an emotional attachment to the task, management, and the company. This in turn can only be developed if they feel fairly treated. And, this in turn is a function of how much voice they have in issues that affect task performance and their well-being (Beer, Spector, Lawrence, Mills, \& Walton, 1985). To ignore employee discontent with the pay system would have meant undercutting the high-commitment culture that had contributed to HP's nearly six decades of outstanding performance. The high performance of other high-commitment companies like Southwest Airlines and SAS Institute, built on many of the same principles as HP (including modest use of pay systems as a means of motivation and narrower spread between the CEO and the lowest-level employee) demonstrates that paying attention to what employees think and feel pays off (O'Reilly \& Pfeffer, 2000).

Given the importance of establishing appropriate performance metrics to the success of pay-for-performance programs, one could question whether the failure of pay-for-performance at HP could have been attributable to limitations in the performance metrics at HP. As we said above, pay-for-performance advocates argue that quantifiable objectives are a key to success. Had HP managers established better metrics, employees might not have been dissatisfied with the pay system. There is no evidence, however, that this was the case in the situations described above. Management by objectives and metrics to measure progress was the cornerstone of Hewlett-
Packard's management philosophy for nearly six decades (Beer \& Rogers, 1995). Moreover, HP managers did invest what they perceived to be considerable time and money in the design and development of metrics for the team-based pay-for-performance program they were introducing. This was not a quick or lightly considered change initiative.

Even if one could convincingly argue that the design of metrics was less than ideally required to implement a pay-for-performance system, it is questionable, given the fastpaced and unpredictable changes in hightechnology companies such as HP, whether such metrics could have been developed at reasonable cost in time and money. Furthermore, it seems questionable whether managers in this case would have embraced such an increase in cost. After all, they already considered the cost of designing and administering the pay-for-performance system onerous given the benefits, and consequently abandoned the system. Additional effort to develop metrics would have further increased the time that these managers would have had to spend managing the system at the expense of time spent in managing and training their employees. This is what they ultimately decided was more beneficial than the pay-for-performance system.

This is not to say, however, that they were not managing effectively in the first place or that such a deficiency had something to do with the failure in implementing pay-for-performance. Hewlett-Packard had always encouraged and expected managers to lead effectively and institutionalized management by objective and managing by walking around, among many other practices, to establish good management as a norm for all managers (Beer \& Rogers, 1995). We found no evidence that this was not also true in the situations described in the cases although we did not focus our investigation on this.

Pay-for-performance advocates argue that the value of a pay-for-performance system lies in the clear differentiation in rewards obtained by high performers compared to low performers. Even if low performers are unhappy with the pay-for-performance
This argument seems to us to ignore decades of evidence that trust and commitment are essential to the capacity of organizations to outperform their competitors. 
So while differentiating performance of individuals or teams is desirable to maintain the perception of fairness, it also has unintended consequences when coordination across individuals and teams is essential for performance. system, high performers are not, the argument goes, and they are the ones who contribute most to organizational performance. Could it be that the pay system introduced at HP did not differentiate sufficiently between high and low performers and/or managers listened to the wrong voices? In fact evidence indicates that the pay-for-performance and skill-based systems were "forcing" differentiation in rewards and that this was an unintended negative outcome. It became very difficult for managers to transfer workers in a low-performing team to a highperforming team (remember that in many cases a team-based pay-for-performance system was introduced). This made redistribution of talent across teams harder (higher-performing teams did not want workers from lower-performing teams) and was one of many reasons HP managers abandoned the system. So while differentiating performance of individuals or teams is desirable to maintain the perception of fairness, it also has unintended consequences when coordination across individuals and teams is essential for performance. We believe the pay system at HP differentiated between high and low performance (a desirable outcome according to pay-for-performance advocates) but that this also contributed to coordination problems that ultimately caused managers to abandon pay-for-performance.

Could it be that HP managers abandoned the pay-for-performance system when it ran into difficulties because, like many managers, they had a penchant for the "program du jour"? Perhaps HP managers are no different than managers in so many other U.S. companies who abandon an improvement program when it runs into difficulties in order to move on to the next fad. Indeed, the tendency of human beings to be overly optimistic, cited earlier, might contribute to this penchant. If this played a role in abandoning pay-for-performance, it would render a serious blow to our interpretation that it was implementation problems inherent in the very conception and design of pay-forperformance systems that caused discontinuation of the pay-for-performance system at HP.
To deal with this question we must understand the root causes of the flavor-of-themonth improvement programs so often seen in corporations. Research suggests that the causes of these programs have to do with their top-down nature (Beer, Eisenstat, \& Spector, 1990a; Beer, Eisenstat, \& Spector, 1990b). Programs fail to be sustained and give way to new programs because top management pushes an improvement initiative through the organization unilaterally, without much involvement or commitment from lower-level managers. They do so to introduce a solution to the organization that they, often with the help of consultants and staff groups (often the HR function), believe to be essential for performance improvement. Because they do not involve lower levels, their overly optimistic evaluation of the potential for success is never challenged. When the improvement program runs into implementation problems in lowerlevel units, such as the ones experienced by unit managers in the HP cases described here, uncommitted managers do not invest enough energy to overcome the problems. However, the HP cases we report on in this article were not introduced from the top nor were they initiated by the HR function. The initiative came from the unit managers closest to the action. These were programs they, not senior management or the HR function, were committed to and thought would improve their business's performance. Therefore, we do not find that it was HP managers' penchant for the "program du jour" that could possibly be the cause for discontinuing the pay-for-performance system. It seems unlikely that they would easily give up on a program for which they felt real ownership. The HP managers made a business-like cost-benefit analysis, as we have argued.

After consideration of the alternative explanations for the failure of pay-for-performance systems at HP discussed in this section, we continue to see our analysis of the cases as correct. While pay-for-performance systems theoretically promise many motivation and performance benefits, researchers and managers have underappreciated the costs incurred when these systems are implemented, particularly in high-commitment systems. 
Michael Beer is the Cahners-Rabb Professor of Business Administration, Emeritus at the Harvard Business School. He has authored many articles and authored or coauthored eight books, among them Managing Human Assets and The Critical Path to Corporate Renewal. The latter received the Johnson, Smith \& Knisely Award and was a finalist for the Academy of Management's Terry Book Award. Professor Beer has served on the editorial board of several professional journals and the board of governors of the Academy of Management. He is a Fellow of the Academy of Management, National Academy of Human Resources, and the Society of Industrial and Organizational Psychology.

Mark D. Cannon is an assistant professor with a joint appointment in Leadership, Policy and Organizations as well as Human and Organizational Development at Vanderbilt University. He has published on executive coaching and has a paper on "transition coaching" for leaders in new positions that will appear in Research in Management Consulting. He investigates barriers to learning in organizational settings, such as positive illusions, individual and organizational defenses, and barriers to learning from failure. His work on learning from failure has appeared in the Journal of Organizational Behavior, and he is co-editor of Organizational Psychology from Dartmouth Publishing Company.

\section{REFERENCES}

Amabile, T. (1988). A model of creativity and innovation in organizations. In B. M. Staw \& L. L. Cummings (Eds.), Research in organizational behavior, 10. Greenwich, CT: JAI Press.

Arthur, J. B., \& Aiman-Smith, L. (2001). Gainsharing and organizational learning: An analysis of employee suggestions over time. Academy of Management Journal, 44, 737-754.

Baker, G., III. (1993). Perspective: Rethinking rewards. Harvard Business Review, 71 (6), 37.

Banker, R., Lee, S. Y., Potter, G., \& Srinivasan, D. (2001). Empirical analysis of continuing performance improvements following incentive plan implementation. Journal of Accounting and Economics, 30, 315-350.

Beer, M., Eisenstat, R. A., \& Spector, B. (1990a). The critical path to corporate renewal. Boston: Harvard Business School Press.

Beer, M., Eisenstat, R. A., \& Spector, B. (1990b). Why change programs do not produce change. Harvard Business Review, 68(6), 158-167.

Beer, M., \& Katz, N. (2003). Do incentives work? The perceptions of a worldwide sample of senior executives. Human Resource Planning, 26(3), 30-44.

Beer, M., \& Rogers, G. (1995). Human resources at Hewlett-Packard (A). Case: Harvard Business School.

Beer, M., \& Spector, B. (1982). Sedalia engine. Case and videos: Harvard Business School.
Beer, M., Spector, B., Lawrence, P., Mills, D., \& Walton, R. (1985). Managing human assets. New York: The Free Press.

Beer, M. \& von Werssowetz, R. O. (1982). Human resources at Hewlett-Packard. Case: Harvard Business School.

Beer, M., \& Weber, J. (2003). Human resource at Hewlett-Packard (C) Case: Harvard Business School.

Bloom, M. (1999). The performance effects of pay dispersion on individuals and organizations. Academy of Management Journal, 42, 25-40.

Bloom, M., \& Michel, J. G. (2002). The relationships among organizational context, pay dispersion, and managerial turnover. Academy of Management Journal, 1, 33-42.

Bonner, S. E., \& Sprinkle, G. B. (2002). The effects of monetary incentives on effort and task performance: Theories, evidence, and a framework for research. Accounting, Organizations and Society, 27, 303-345.

Burrows, P. (2003). Back fire: Carly Fiorina's highstakes battle for the soul of Hewlett-Packard. New York: Wiley.

Business: Pay purview. (1998). The Economist, 348, 8083, 59-60.

Collins, J., \& Porras, J. (1994). Built to last. New York: Harper Business

Deci, E. L., \& Ryan, R. M. (1985). Intrinsic motivation and self-determination in human behavior. New York: Premium. 
Fay, C. H., Thompson, M. A., \& Knight, D. (Eds.). (2001). The executive handbook on compensation. New York: The Free Press.

Gerhart, B. (2001). Designing reward systems: Balancing results and behaviors. In C. H. Fay, M. A. Thompson, \& D. Knight (Eds.), The executive handbook on compensation (p. 235). New York: The Free Press.

Gerhart, B., \& Rynes, S. L. (2003). Compensation: Theory, evidence, and strategic implications. Thousand Oaks, CA: Sage.

Gibson, V. M. (1995). The new employee reward system. Management Review, 84(2), 13-18.

Gomez-Mejia, L. R., Welbourne, T., \& Wiseman, R. M. (2000). The role of risk sharing and risk taking under gain sharing. Academy of Management Review, 25, 492-507.

Graham, M. E., \& Welbourne, T. M. (1999). Gain sharing and women's and men's relative pay satisfaction. Journal of Organizational Behavior, 20, 1027-1043.

Hamner, C. (1975). How to ruin motivation with pay. Compensation Review, (3rd quarter), 88-98.

Hein, K. (1996). Raises fail, but incentives save the day. Incentive, 170, 11.

Heneman, R. L., Ledford, G. E., Jr., \& Gresham, M. T. (2000). The changing nature of work and its effect on compensation design and delivery. In S. L. Rynes \& B. Gerhart (Eds.), Compensations in organizations (pp. 195-240). San Francisco: Jossey-Bass.

Hollensbe, E. C., \& Guthrie, J. P. (2000). Group pay-for-performance plans: The role of spontaneous goal setting. Academy of Management Review, 25, 864-872.

Kahneman, D., \& Tversky, A. (1979). Prospect theory: An analysis of decision under risk. Econometrica, 47, 263-291.

Kohn, A. (1993). Why incentive plans cannot work. Harvard Business Review, 71(5), 54.

Lawler, E. E., \& Hackman, J. R. (1969). The impact of employee participation in the development of pay incentive plans: A field experiment. Journal of Applied Psychology 53, 467-471.

Luthans, F. \& Stajkovic, A. D. (1999). Reinforce for performance: The need to go beyond pay and even rewards. Academy of Management Executive, 13(2), 49-57.

Meyer, H. (1975). The pay-for-performance dilemma. Organization Dynamics, 3, 39-50.

Miceli, M. P., \& Mulvey, P. W. (2000). Conse- quences of satisfaction with pay systems: Two field studies. Industrial Relations, 39, 62-87.

O'Reilly, C. A., \& Pfeffer, J. (2000). Hidden value: How great companies achieve extraordinary results with ordinary people. Boston: Harvard Business School Press.

Peach, B., \& Wren, D. A. (1992). Pay-for-performance from antiquity to the 1950s. Journal of Organizational Behavior Management, 12, $5-21$.

Pearce, J. L., Stevenson, W. B., \& Perry, J. L. (1985). Managerial compensation based on organizational performance: A time series analysis of the effects of merit pay. Academy of Management Journal, 28, 261-278.

Pfeffer, J. (1998). Six dangerous myths about pay. Harvard Business Review, 76(3), 108-119.

Pfeffer, J., \& Sutton, R. I. (2001). The knowingdoing gap: How smart companies turn knowledge into action. Boston: Harvard Business School Press.

Rigby, D. (2001). Management tools and techniques: A survey. California Management Review, 43(2), 139-160.

Schuster, J. R. \& Zingheim, P. K. (1992). The new pay: Linking employee and organizational performance. New York: Lexington.

Shaw, J. D., Gupta, N., \& Delery, J. E. (2002). Pay dispersion and work force performance: Moderating effects of incentives and interdependence. Strategic Management Journal, 23, 491-512.

Stajkovic, A. D., \& Luthans, F. (2001). Differential effects of incentive motivators on work performance. Academy of Management Journal, 44, 580-590.

Sturman, M., \& Short, J. C. (2000). Lump-sum bonus satisfaction: Testing the construct of validity of a new pay satisfaction dimension. Personnel Psychology, 53, 673.

Taylor, S. E., \& Brown, J. (1988). Illusions and wellbeing: A social psychological perspective on mental health. Psychological Bulletin, 103, 193-210.

Van Eerde, W., \& Thierry, H. (1996). Vroom's expectancy models and work-related criteria: A meta-analysis. Journal of Applied Psychology, 81, 575-586.

Vroom, V. H. (1964). Work and motivation. New York: Wiley.

White paper: Alternative pay programs at HP, Palo Alto, California. (1994). Hewlett-Packard document. 


\section{"PROMISE AND PERIL IN IMPLEMENTING PAY- FOR-PERFORMANCE" BY MICHAEL BEER AND MARK D. CANNON}

\section{Commentary by James N. Baron}

We promise in proportion to our hopes, and we deliver in proportion to our fears.

François La Rochefoucauld, Moral Maxims and Reflections

Professors Beer and Cannon underscore some important points about reward systems, which apply far beyond HewlettPackard. First, some conditions that make pay-for-performance (PFP) especially desirable or feasible may also, paradoxically, make it especially tough to implement. For instance, the trust HP had engendered among its workforce also meant management had more to lose reputationally if/when things turned sour. Having captured employees' hearts and minds, HP was especially vulnerable to the "ratchet effect" (as in the San Diego experiment) and the danger of undercutting intrinsic motivation, loyalty, and teamwork by overemphasizing financial incentives.

Like HP, companies implementing PFP often confront challenging and turbulent environments, which is part of what makes it appealing to tie financial rewards to increases in output or quality. Yet, as Beer and Cannon note, this environmental uncertainty and volatility can make PFP hard to implement, because of the difficulty in determining how much measured results reflect employees' efforts versus factors outside their control (as at Colorado Memory Systems). Moreover, when the environment is uncertain and rapidly changing, results will fluctuate markedly over time regardless of what employees do, simply due to random events. Because employees generally dislike wildly oscillating pay, variations over time in PFP payouts may be a disincentive.

This is especially true given the reasons for expecting positive, but fleeting, initial effects when PFP is first introduced, including: Hawthorne effects; "low-lying" improvements to be realized; and the fact that workers are anchored on what their pay used to be, so any supplementary pay represents a "bonus." If initial payoffs are generous, employees begin anchoring against what they received when the plan paid out most handsomely; a shortfall relative to this anchor may seem like a penalty, not a "smaller bonus." All too often, however, initial PFP payouts are modest, as Beer and Cannon imply was true for at least some of HP's experiments. When initial payoffs are low, the losers may still bitterly resent being placed at the bottom of the heap, while the winners won't have won very much.

HP's experiments also highlight how pay plans depend vitally on the entire constellation of human resource practices and values in which they are embedded. For example, the Boise facility struggled to implement peer evaluations as part of its PFP experiment, in a context that did not support this. It may have appeared tempting to new management at HP to move away from the less formal, more implicit controls the firm employed historically, 
toward a more balanced mix incorporating some formal and explicit controls. Yet it's not clear in this case that the middle ground is a better place to be than at one of the extremes.

This point is illustrated by some findings from the GLOBE project, a recent collaboration between some of us at Stanford Business School and McKinsey \& Company. GLOBE examined how large global corporations seek coordination worldwide while maintaining local flexibility. Interviewing senior executives in prominent global companies in the United States, Europe, and Japan, we identified various "control levers" from which leaders seemed to be choosing. These levers clustered into two distinct groups. One group involved "harder," more explicit controls: incentive systems, standardized processes, and use of metrics. The second cluster involved "softer" levers: enculturation, personal networks, and corporate strategy statements. Companies relying on one lever within each group tended also to rely on the others within that cluster.

We constructed scales measuring each firm's reliance on hard and soft controls, which attained their maximum values when a company utilized all three levers within the hard or soft cluster. Figure 1 portrays 16 GLOBE companies along these two dimensions. Firms that were moderate to high on one dimension were generally low on the other. Firms tended toward one pole or the other; hard and soft controls served as alternatives among these large global companies. One conspicuous exception is the firm circled in the figure, considerably above the sample average on both dimensions. This company was Enron in 1999-2000. Some post-mortems have emphasized how Enron's leadership sent confusing signals about what it valued and expected-put differently, their soft levers, such as strategy, networks, and culture, didn't necessarily align with the intense emphasis on metrics and incentives.

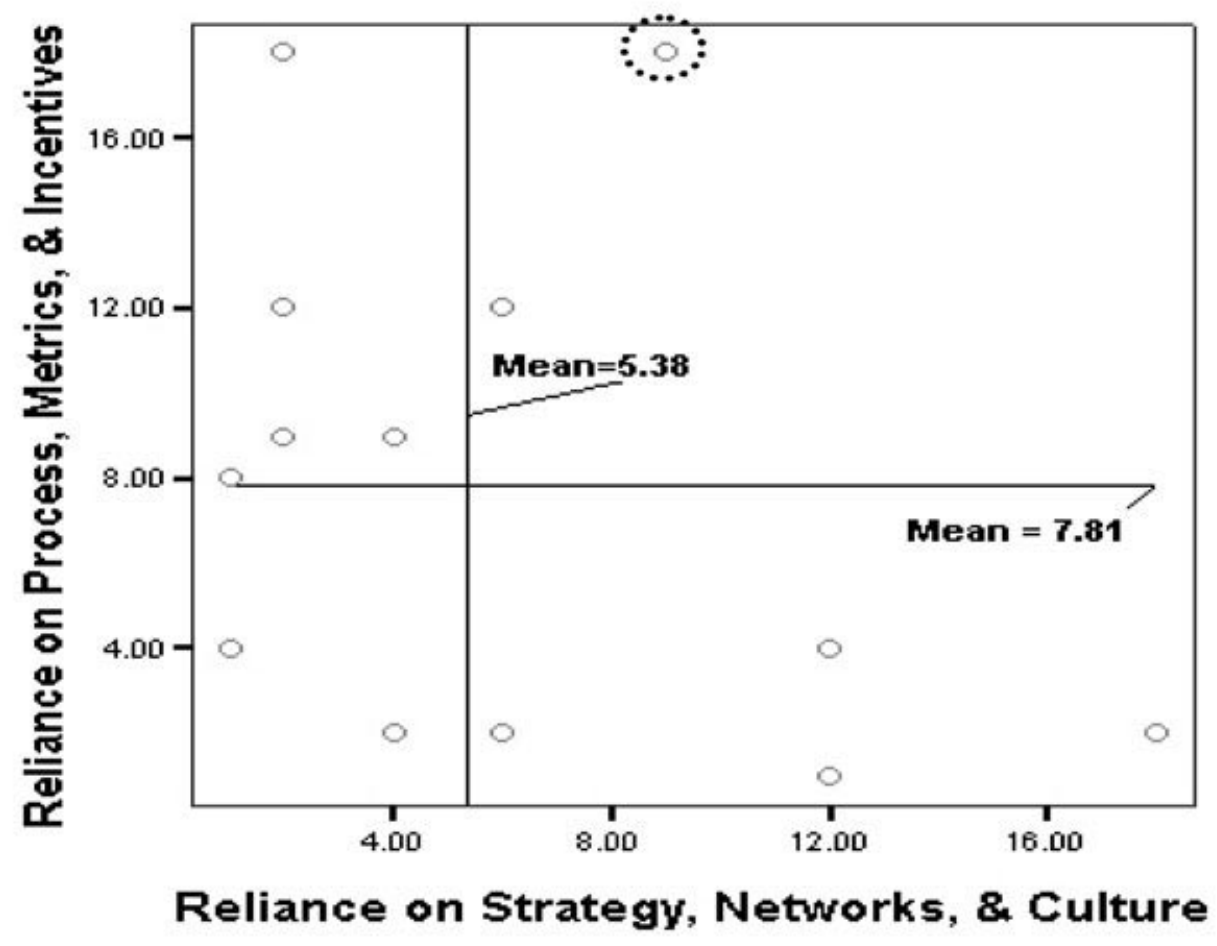

Figure 1. Reliance on "Hard" and "Soft" Drivers of Coordination in 16 Global Corporations. Source: Stanford/McKinsey GLOBE Study. 
Admittedly, Enron is only one data point. Yet Beer and Cannon's account of PFP experiments at HP can be read as the story of a quintessential "soft control" company trying to move closer to the 45-degree line in Figure 1. The risk of such experiments is that the organization shifts from being an ideal example of something to a mediocre example of everything, thus becoming a clear example of nothing.

Beer and Cannon make a strong case that PFP can have unexpected, even adverse, effects on organizations. In my view, it is not PFP per se that is dangerous, but rather systems that excessively emphasize financial rewards for performance. As Ronald Dore wrote in discussing piece rates:

There is a further, intangible cost in disaffection and suspicion. Because the whole system is geared to keep their earnings level constantly in the workers' consciousness, they carefully calculate what their earnings ought to be. ${ }^{1}$

Instead of pay for performance, we should be thinking more broadly about re- wards for performance. Should professors be rewarded, even financially, for outstanding teaching? Absolutely. Should HR professionals be rewarded, even financially, for delivering superior service to their clients? Sure. But imagine being a student in a class and knowing your professor has a huge financial stake in the course evaluations or in your standardized test score. Or imagine working in a company whose HR staff have enormous incentives based on your "customer satisfaction rating" or on processing your inquiry hastily. For the jobs that increasingly characterize our economy, it's not just about what people do or the quantity they produce; it's about how they relate to their work and what motivates them to excel. Like Beer and Cannon, I suspect PFP plans will attain superior results when their framing, communication, and implementation don't batter employees over the head with financial attributions for their behavior.

\section{NOTE}

1. Dore, R. (1973). British factory, Japanese factory. Berkeley: University of California Press; p. 83 (emphasis in original).

James N. Baron is the Walter Kenneth Kilpatrick Professor of Organizational Behavior and Human Resources at Stanford Business School. His research focuses on the determinants and consequences of organizational structures and human resource policies, particularly their effects on workers' careers and organizational performance. With David M. Kreps, he is the author of Strategic Human Resources: Frameworks for General Managers (Wiley, 1999). Professor Baron has been a consultant on strategic, organizational, and human resource issues to corporations, law firms, government agencies, and nonprofits. He currently serves on the advisory boards of relatia.com, BeyondWork, and SkyVenture Silicon Valley. 


\section{"PROMISE AND PERIL IN IMPLEMENTING PAY- FOR-PERFORMANCE" BY MICHAEL BEER AND MARK D. CANNON}

\section{Commentary by Patrick R. Dailey}

"Good strategy followed by great implementation" trumps "great strategy followed by good implementation." It seems like this is always a truism. And Beer and Cannon's case analyses support this premise. Overall, the analyses were instructive, yet I felt in somewhat of a "time warp," with analysis completed in the early 1990s used to make contemporary points and argue current issues. Perhaps many of these conclusions are enduring insights into the dilemma of implementing pay-for-performance systems. Yet, as I describe below, including Carly Fiorina's leadership agenda into the interpretative comments seems to be an error in timing and attribution of cause and unintended effect.

As the now former head of Global Workforce Management for HP during a significant part of Carly's tenure, I offer my comments with the hopes of being insightful.

\section{It is wrong to connect Carly Fiorina with} the outcomes of these experiments. The text connects these experiments in variable compensation with Carly's broad cultural change agenda and suggests that poor management of these experiments was a missed opportunity for change. It must be noted that the experiments occurred in the very early 1990s; Carly did not arrive with her change agenda until 2000. These experiments were conducted during a time of very steady state cultural conditions at HP and during a time when perfor- mance was relatively robust. As the 1990s came to a close, HP fell upon a series of financial quarters in which the company failed to perform and experienced losses. So, these experiments were truly local experiments, and not part of any large-scale cultural change initiative. These were not missed change opportunities in the sense of renewing vision, values strategies, and operational approaches. Fundamental change was not on the agenda at the time of the experiments.

2. Fundamental principles of good change management seem to be missing in all of these experiments. They were local "tweaking," in fact, "add-on" compensation elements to the existing pay system. To use these experiments to make a fundamental assessment of pay-for-performance systems conceptually seems to be a reach for this reader. The experiments were optional, apparently were not part of a broad revisioning process, and failed to put pay at risk to any significant level. These spotty experiments across an organization that shares information widely might have been seen as a signal that things "might be changing," and thus I agree with the authors' comments about "informal negotiation" that occurs when change is poorly sold and its implementation lacks managerial support for longevity. A fundamental "values statement" for making these changes seems to be missing in the implementation. 
The success of PFP programs is highly contingent on the ability to measure these differences and the willingness of managers to apply rewards differentially.
3. Change is complex. And something as fundamental as the difficulties associated with change compensation systems was underestimated by the local managers. The authors noted this, but could develop this issue more. The cross-functional/teaming culture of the HP organization would lead people to know the elements and operational details of these programs, and, true to the culture, participants would be inclined to "pick and choose" elements from any of the experiments and "negotiate" for the most desirable elements from all of these experiments. Any downside of any one program would be construed as an "unfair" takeaway by employee participants. The authors appropriately discussed "expectancy theory," and in most cases the issues of "attractiveness" and "attainable" benefits from the behaviors being rewarded are discussed in the context of "employees," not managers. I suspect with the inept positioning of the programs, a lack of long-term ownership to the program, and lots of questions and concerns from knowledge workers, that expectancy theory would predict that managers' motivation for continuing the experiments might be quite low. Going forward was just not worth the hassle to the managers and, frankly, it appears the pay out of \$150-200 per month is not a life-changing level of compensation. Perhaps the programs and their payout defaulted to a level of a nuisance to the managers and not attractive enough for employees-especially when no pay was at risk - to build excitement and emotional commitment. From a change management perspective, there was not a "burning platform" for continuing these experiments and no penalty for poor implementation. Managers had low commitment to stay the course, it appears. In summary, the experiments failed to appreciate the context of the initiatives and the content of the programs themselves.

4. The risk/return issues of various organizational change initiatives would be a very productive topic for the authors to focus more attention on. The authors compared the impact of poor implementation of one type of intervention-i.e., a training program-versus the poor implementation of a compensation program. What are the potential upsides? What are the potential downsides?
5. Pay-for-performance requires pay systems and managers to encourage certain selected behaviors and reward differentially the resulting outcomes. Certain cultures are more or less willing to differentiate individual or team contribution. The success of PFP programs is highly contingent on the ability to measure these differences and the willingness of managers to apply rewards differentially. I would like to see more attention to these matters in the discussion the authors provide.

6. HP has a long reputation for "startstop" practices on many things. This may be the fundamental explanation of the demise of these efforts.

7. Words are important. The manner in which an initiative is introduced and described has important implications in the perception of the initiative. For a highly competent engineering professional to be "subjected" to being part of an experiment could negatively impact a current level of trust and commitment in a new process. Few of us want to be "guinea pigs." I wonder how these experiments were described to the participants, in contrast to how the early Roethlisberger and Dickson studies on workplace illumination that were used to coin the concept of Halo Effect-with its positive effectswere described to the participants. Why did "experimentation" work in one condition (Western Electric) and not in another (HP)?

In summary, I applaud the authors' focus on the perils of implementation and hopes that more energy is invested in learning the keys to "great implementation"- the real differentiator in change management initiatives. I particularly appreciate investigation into the efficacy of program implementation in contrast to investigation into theoretical concepts.

However, these experiments and the discussion seem to be anecdotal rather than fundamental to the investigation of pay-forperformance concepts and initiatives. It is a "reach" to base assessment of pay-for-performance systems on experiments conducted more than ten years ago-even with the authors' disclaimers. Implementation issues are extremely important to successful outcomes 
and the authors are "on to" issues that are important to ultimate outcomes and organizational success.

It appears that these compensation experiments largely failed and faulty implementation is the culprit-yet there are so many unmentioned, uncontrolled independent variables operating in these experiments that it is difficult to draw anything more than interesting anecdotal insights from the case analyses.
The final conclusion is that pay-for-performance programs may be unproductive instruments for influencing behavior and results due to their high "costs" of implementation. Basically, these initiatives are perhaps too tough to manage. The authors make a persuasive case, but I do wish the authors had offered recommendations that might remedy the unproductive outcomes from the experiments reported in the core of the article. That is where the value in reading this article could have been derived.

Patrick R. Dailey, PhD, is a senior human resources generalist with expertise in talent management and the implementation of large-scale change initiatives for major global companies including Hewlett-Packard, Lucent Technologies, and PepsiCo. He is a frequent contributor to the editorial critique of articles submitted to our journal. Mr. Dailey was originally trained as an industrial and organizational psychologist. 


\section{"PROMISE AND PERIL IN IMPLEMENTING PAY- FOR-PERFORMANCE" BY MICHAEL BEER AND MARK D. CANNON}

\section{Commentary by Barry Gerhart}

The Beer and Cannon study tells a convincing and important story about the "peril" part of the "promise and peril" of pay-forperformance plans. Part of the peril experienced at HP may have been due to inadequate "due diligence" regarding the key issue of fit, both between the new pay programs and the business and human resource strategies, and between the new pay programs and the existing HP workforce(s). Another problem may have been a lack of homework regarding the typical risks of variable pay plans. It is well known that these plans, when applied to blue-collar jobs, often flounder because of problems with setting and maintaining a performance standard that is seen as fair by both management and workers (Gerhart \& Rynes, 2003; Whyte, 1955). This problem is exacerbated to the degree that changes in technology, product markets, and so forth require frequent standard revision.

Even where such issues are understood and anticipated, variable pay plans of the sort used at HP are known to be risky. Indeed, I have cautioned, "One must consider whether the potential for impressive gains in performance" from such plans is "likely to outweigh the potential problems, which can be serious" (Gerhart, 2001, p. 222) and that such plans are best thought of as representing "a high risk, high reward strategy" (p. 222).

We (Gerhart, Trevor, \& Graham, 1996) have addressed the risks associated with pay- for-performance plans in some detail, noting, for example, that although success stories tend to receive the most attention, it is at least as informative to study the many instances of plans not surviving for any significant period of time. The Beer and Cannon article is very helpful in providing specific examples of how this can happen, even in a company that is generally viewed as having strong and capable management.

I also agree with Beer and Cannon's argument that companies already having strong employee relations may have the most to lose (or most at risk) in "experimenting" with the types of pay-for-performance programs they describe. A company like HP has followed a particular historical path that has resulted in its current unique culture and employee relations. Any program that would potentially damage this long-nurtured intangible asset should indeed be considered with great caution.

Consistent with Beer and Cannon's general message, however, not all companies are like HP. Context probably matters. Some companies must change. These companies may choose to make important changes in HR. Other companies (or some of their facilities) may be in a start-up phase where it is easier to shape HR practices unencumbered by history and these, in turn, may shape a workforce that fits those practices. Indeed, it is difficult to understand why a company like HP, having apparently made no compelling

Correspondence to: Barry Gerhart, University of Wisconsin-Madison, School of Business, 975 University Ave., Madison, WI 53706, Tel: (608) 262-3895, (608) 265-5372, E-mail: bgerhart@bus.wisc.edu 
Beer and Cannon, in a few instances, make general statements about pay-forperformance that go beyond the HP data and which are not necessarily supported... case for change and having the same workforce and culture today that it had yesterday, would expect its "experiments" with pay programs to be well received. The only rationale described for the experiments seemed to be an interest in a mechanical ad hoc "quick fix" to some problem. Beer and Cannon provide evidence that variable pay programs do not necessarily provide this quick fix.

In speaking of context, Beer and Cannon ascribe to me (Gerhart, 2001) the argument that "a pay-for-performance program might be more easily implemented" (Beer \& Cannon, p. 5) in organizations having certain characteristics. These (directly quoted from my chapter) are: "(1) the culture discourages opportunism, (2) top management reinforces this culture by example, and (3) employees have long-term careers or professions in which their reputation is a valuable commodity" (p. 235). They argue that HP has these characteristics, but was nevertheless unsuccessful in implementing variable pay. Thus, these three factors may not explain implementation success. To clarify, I did identify these three factors, but not as contingency factors in explaining how "easily implemented" a program would be and not in the context of a plan geared toward blue-collar workers (the focus of the HP experiments). Rather, my focus was on how these three factors might "reduce" the "significant risks" (p. 234) of such plans, especially the risk of "opportunism" and the examples I gave of opportunism included four instances of companies that were sued because their executive or professional employees engaged in opportunistic behavior that was unethical or illegal, arguably in response to incentive systems. This distinction was perhaps not sufficiently clear in Gerhart (2001). I hope it now is.

Having spoken to the substance of the hypothesis, let me now clarify what would constitute an informative test. If one did wish to test whether certain organization factors moderate the effectiveness of pay programs, it is clearly not possible to do so using data from a single (i.e., $N=1$ ) company. With no comparison companies, there is no way of knowing whether implementation would have gone better or worse at companies having different characteristics (than
HP in this example). To understand its impact, we must have a design that provides variance in context.

For the same reason, we should not generalize too much from experiences at a single company. Pay-for-performance programs for blue-collar workers have survived and been integrated into the culture at other companies (e.g., Kraft, Lincoln Electric, Nucor, GE). So while Beer and Cannon do an excellent job of demonstrating the peril, we should not completely dismiss the promise aspect. However, consistent with their general argument, established companies may encounter more barriers and more risks than companies (or facilities) that begin with variable pay as part of their fundamental makeup.

Beer and Cannon, in a few instances, make general statements about pay-for-performance that go beyond the HP data and which are not necessarily supported, in my view, by the broader literature. Contrary to their discussion on p. 4, I do not believe there is any evidence from employment settings to show that pay-for-performance plans necessarily harm intrinsic motivation or creativity (Gerhart \& Rynes, 2003). The notion that pay-for-performance harms teamwork (p. 4) is certainly plausible under some conditions, but depends on the design of the program. Further, it is important to recognize that (individual) pay-for-performance can have beneficial effects via attraction-selection-attrition (Schneider, 1987) such that better performers stay and others leave in organizations where pay and performance are strongly linked (Trevor, Gerhart, \& Boudreau, 1997). Teamwork likely has a bigger payoff when individual team members are strong.

Finally, I would perhaps give more weight than Beer and Cannon do to the competence of "local management," the apparent drivers of the pay-plan changes at HP. As noted earlier, it is not clear that they did their homework. Indeed, the plans were described as "experiments," which suggests this may have been lacking. Although understanding, awareness and anticipation of potential problems with variable pay certainly does not eliminate the risk, it should improve the odds of making a good decision and implementing it successfully. 
In closing then, let me make the following suggestions to any company (or manager) considering a new variable pay program. First, by all means, read Beer and Cannon's article. Then, tap into others' experiences with such plans. Learn from both the successes and the failures. After that, consider whether a compelling rationale for a change can be made and how it will better support the business objectives. Next, consider whether other aspects of the HR system (e.g., the current workforce, performance assessment, employee input, work design) will fit the proposed change. If not, how will this issue be addressed? If the plan is to move ahead, get input from employees before a decision is made (and afterward). Lastly, review the promise and peril, both of acting and not acting, and then decide.

BARRY GERHART is professor of management and human resources and the John and Barbara Keller Distinguished Chair of Business, School of Business at the University of Wisconsin-Madison. His previous faculty appointments include serving as chair of the organization studies area at Vanderbilt University's Owen Graduate School of Management and as chair of the Department of Human Resource Studies at Cornell University. His major fields of interest are human resource management and strategy, compensation, and business performance. Professor Gerhart received his BS in psychology from Bowling Green State University and his $\mathrm{PhD}$ in industrial relations from the University of Wisconsin-Madison. Current and past editorial board appointments include the Academy of Management Journal, Administrative Science Quarterly, Industrial and Labor Relations Review, the International Journal of Human Resource Management, the Journal of Applied Psychology, and Personnel Psychology. In 1991, Professor Gerhart received the Scholarly Achievement Award from the Human Resources Division, Academy of Management. He is also a Fellow of the American Psychological Association and of the Society for Industrial and Organizational Psychology. Professor Gerhart is co-author of the recent book, Compensation: Theory, Evidence, and Strategic Implications, as well as co-editor of Compensation in Organizations, and coauthor of Human Resource Management: Gaining a Competitive Advantage.

\section{REFERENCES}

Gerhart, B. (2001). Designing reward systems: Balancing results and behaviors. In C. H. Fay (Ed.), The executive handbook on compensation (pp. 214-237). New York: The Free Press.

Gerhart, B., \& Rynes, S. (2003). Compensation: Theory, evidence, and strategic implications. Foundations for Organizational Science series. Thousand Oaks, CA: Sage.

Gerhart, B., Trevor, C., \& Graham, M. (1996). New directions in employee compensation research.
In G. R. Ferris (Ed.), Research in personnel and human resources management (pp. 143-203). Oxford, UK: JAI Press/Elsevier.

Schneider, B. (1987). The people make the place. Personnel Psychology, 40, 437-453.

Trevor, C., Gerhart, B., \& Boudreau, J. W. (1997). Voluntary turnover and job performance: Curvilinearity and the moderating influences of salary growth and promotions. Journal of Applied Psychology, 82, 44-61.

Whyte, W. F. (1955). Money and motivation. New York: Harper's Brothers Publishers. 


\section{"PROMISE AND PERIL IN IMPLEMENTING PAY- FOR-PERFORMANCE" BY MICHAEL BEER AND MARK D. CANNON}

\section{Commentary by Herbert G. Heneman III}

This is a very interesting and unique article. While reports of multiple failures are rarely published, it is important for them to be. From these instances, perhaps we can discern meaningful lessons about how to prevent failure in the future. In this regard, the authors seek to inform us on two underresearched issues - namely, the implementation of pay-forperformance plans, and managerial decision making regarding their initiation, modification, and discontinuation. I would like to add to the speculation as to why the plans failed and suggest that the case descriptions are potentially lacking some critical information as to specific practices.

The five pay plans encountered, in varying degrees, implementation and maintenance problems. In each instance, the design of the plan by the site manager went awry during implementation, with a host of problems surfacing to bedevil the plan and the manager. As I read these five cases, I was struck by the familiarity of problems: validity of performance measures, contamination of performance by extraneous forces, fluctuating performance standards, counterproductive team-member behaviors, unfamiliar performance assessments (e.g., peer evaluation), insufficient payouts, fluctuating payouts, and so forth. There is nothing new on the list; all the problems have been uncovered by previous research and known for some time.

This raises the obvious question: Why did all of these problems occur? We are told that the company "had in place many of the conditions that should lead to success." Clearly these were not sufficient. Let me suggest some potentially missing conditions. First is a lack of knowledge and skill regarding pay-for-performance plans among the site managers. We are told that the managers had considerable discretion in the decision to experiment with pay-for-performance plans, which they exercised on their own without initiation by (or assistance from?) the HR function. Though we lack information, it seems plausible that naïve managerial discretion underlay use of the complex behavioral tool of performance pay. While the plans' designs may have appeared to be technically sound performance boosters, the managers may have failed to anticipate the many behavioral problems that became "unintended consequences." Managers with behavioral savvy would have taken steps up front to help avoid these problems or perhaps never have undertaken the plan in the first place. This interpretation is consistent with the authors' observation about the "overly optimistic assumptions" managers made about time and administration requirements and benefits that would be achieved.

A second missing (at least not reported) condition is attempts to facilitate implementation with the use of other mechanisms that typically accompany the introduction of pay-for-performance plans, particularly formal communication and training programs.

Correspondence to: Herbert G. Heneman III, University of Wisconsin, School of Business, 975 University Ave., Madison, WI 53706-1323, Tel: (608) 263-3461, (608) 262-8773, E-mail: hheneman@bus.wisc.edu 
For the most part, the pay plans were quite complex, and inadequate communication about plan purpose, procedures, performance measures, and so forth may have helped sow discontent. Likewise, inadequate training for managers and employees may have kept them from having the necessary knowledge and skills for functioning successfully within the plan. For example, three of the plans used special performance assessment systems that were a substantial departure from the merit system the employees were accustomed to. These were skill assessments (San Diego site), peer evaluation (Boise Printers Formatter Shop), and a nomination and approval process (Workstation Group). In short, there appears to be a lack of supportive programs that would help employees and managers adapt to the new payfor-performance plans.
A final, possibly missing condition is the HR department or function. Where was it during the design, implementation, and maintenance of the pay-for-performance plans? It sounds as though, with a certain source of pride, that HR was intentionally kept on the sidelines so that individual site managers could be in control and make their own choices. If indeed HR was kept at bay, I submit this was a flawed decision that also contributed to the pay plans' demise. Quite simply, pay-for-performance plans require substantial specialized expertise to design and implement, and such expertise is unlikely to be found in line managers. Unfortunately, we do not know the level and availability of payfor-performance expertise among the HR staff at HP, so we must be cautious in assuming that their exclusion worked to the detriment of the pay-for-performance plans.

Herbert G. Heneman III is the Dickson-Bascom Professor, Emeritus, in the Business, Management and Human Resources Department at the University of Wisconsin-Madison. He also serves as a senior research associate in the Wisconsin Center for Education Research. He has been a visiting faculty member at the University of Washington and University of Florida and was University Distinguished Visiting Professor at Ohio State University. His research is in the areas of staffing, performance management, union membership growth, work motivation, and compensation systems. He currently is investigating the design and effectiveness of performance management and compensation systems for schoolteachers and is on the Board of Directors of the Society for Human Resource Management Foundation and is its vice president for research. He is the senior author of four textbooks: Managing Personnel and Human Resources: Strategies and Programs (1981), Perspectives on Personnel/Human Resource Management 3/e (1986), Personnel/Human Resource Management, 4/e (1989), and Staffing Organizations, 4/e (2003). He is a Fellow of the Academy of Management, former chair of its Human Resources Division, and recipient of the Division's Career Achievement Award. He is also a member and Fellow of the American Psychological Association and the Society for Industrial and Organizational Psychology. Other memberships include the Industrial Relations Research Association, the American Educational Research Association, the Society for Human Resource Management, the International Personnel Management Association, and the World of Work. 


\section{"PROMISE AND PERIL IN IMPLEMENTING PAY- FOR-PERFORMANCE" BY MICHAEL BEER AND MARK D. CANNON}

\section{Commentary by Thomas Kochan}

\section{Back to the Future}

Yogi Berra has long been recognized as one of America's most prescient baseball philosophers, but little did we know he could also foresee the future of the human resource management profession. Yogi's famous statement that "it's like déjà vu all over again" came to mind as I read Michael Beer and Mark Cannon's analysis of failed pay-forperformance systems at Hewlett-Packard. Even more pointedly, it reminded me of the annual visit of Fred Lesieur to my HR classes at MIT in the early 1980s. Fred was the protégé of Joseph Scanlon, the Steelworkers' Union official who invented one of America's most enduring pay-for-performance plans, appropriately labeled the "Scanlon Plan" (Lesieur, 1957).

Each year, Fred would entertain (and educate) my students with real-life examples that illustrated why most incentive pay plans fail. He liked to use their professor as cannon fodder to drive home the four principles underlying the Scanlon Plan and other payfor-performance plans.

He stressed that for performance plans to be successful and sustainable they must:

1. Provide for independent employee voice and participation in (a) the decision to initiate a new plan, (b) its design, (c) the generation of sugges- tions for continuous improvement, and (d) the plan's administration and adjustment;

2. Cover all employees in a facility so as to encourage cross-occupational and cross-level cooperation, not competition;

3. Build on, and not substitute for, fair base wages and benefits; and

4. Recognize that the Achilles' heel of any performance sharing formula lies in the challenges posed to it by changes in technology, market conditions, product mix, or organizational strategies and leadership.

These principles pretty much capture what Beer and Cannon report happened in these HP cases. Let's be more specific.

The fact that HP had a "reputation for high commitment and high trust" should not have led management to expect workers to be passive and uninterested in having a voice in management decisions to alter their compensation system. Unfortunately for the HP employees, and ultimately for the advocates of these plans, Beer and Cannon report that employees were not involved in the decisions to introduce these plans nor did they have any voice in their administration. So Scanlon's Principle \#1 was violated in all of the cases reviewed, and as the authors suggest, in all other 


\section{Don't use an incentive plan to try to close a gap between current wages and what employees perceive to be the fair wage.}

parts of the company that tried and then abandoned similar plans.

Indeed, the HR professionals at HP apparently were so desensitized to the need for independent employee voice that it did not occur to them to consider the need to build this feature into their plans. Instead, they naïvely, and it turns out wrongly, expected employees to just trust management to design the plans and take care of employee interests. The corporate scandals of the past several years that came on top of a decade of increasing workforce pressures should serve as the final nail in the coffin of the naïve view that employees should or will just trust top management and its HR partners to take care of their welfare. There is probably not an employee in America who still believes this, even in companies that had a reputation for high commitment and trust.

Beer and Cannon note that most of these plans covered blue-collar workers, not the entire labor force in a plant. This violates Scanlon's Principle \#2. This feature becomes even more problematic in facilities like some of those described here, where HP was simultaneously "delayering" and pushing decisionmaking authority down to lower levels. While it is not mentioned in the case studies, I would be very surprised if there did not exist a cadre of middle managers and former first-line supervisors who saw their jobs and positions being "delayered" who were outside the scope of these plans, resented them, saw them as unfair, and used their considerable and varied sources of power to undermine them. At the very least, I would be astounded if there were not some who chortled "I told you so" after the fact.

The San Diego example illustrated the problem of designing pay systems with different payouts to "autonomous or self-managing work teams" in an interdependent production system. Because the payout scheme was team-based, Beer and Cannon report some teams "often refused to admit anyone to their team who they thought might be below their level of competence." Such a scheme does not promote plantwide cooperation, a key requirement in any sustainable pay-for-performance program.

The Colorado case illustrates Scanlon Principle \#3: Don't use an incentive plan to try to close a gap between current wages and what employees perceive to be the fair wage. The takeover of this facility by HP not only quashed workers' expectations that they would share in the gains expected from an anticipated stock offering, but they also found that their wages were considerably below those of HP employees in other facilities. So this plan started from a position of distrust and dissatisfaction. While management hoped the plan would be the vehicle for closing the pay gap, it failed to do so. Lo and behold, the program never gained credibility with employees.

Robert McKersie and Laurence Hunter captured the essence of Scanlon Principle \#4 in their study of productivity bargaining programs in Britain in the 1960s and 1970s. They noted that there is a "powerful tendency for all incentives to deteriorate" over time and that the revision of any incentive pay scheme is always likely to be more difficult and more closely watched by employees than its initial design (McKersie \& Hunter, 1973, p. 150). Why is this the case, perhaps even more so now than before? The basic reason is that, particularly in today's dynamic and uncertain world, organizations are constantly changing. Changes in technologies, market conditions, business strategies, organizational leadership, etc., all are likely to affect the payouts produced by pay-for-performance formulas. Therefore, a strategy for coping with and adjusting to these changes has to be built into the plan. And in today's information-savvy workforce, the effects of these larger organizational strategies and changes on the plan and its payout potential must be transparent and communicated effectively to the workforce. Today's workers are watching and scrutinizing top management actions and market developments ever so closely and have the tools to communicate with each other quickly and easily. All HR strategies need to address this increased interdependence between strategic management decisions and actions and workforce perceptions of fairness and behavior.

When Lesieur spoke to my classes, he loved to shock students and kid me by saying that in plants that either were about to undergo major changes, or where the future was uncertain or highly variable, the best 
pay-for-performance plan was no plan. Then he would turn to me and say, "To try to implement a new plan in such a setting just makes more work for labor arbitrators like your good professor." The students loved it, partly for the humor, but more because here was a consultant willing to tell them and prospective clients that his program, and others like it, would not work in all settings.

Of all the examples reviewed by Beer and Cannon, only the Workstations Group case appears to have been viewed as a success, although both managers and employees seem to attribute the success of the operations to more intrinsic motivational factors than to the bonus plan. And the bonus plan was not introduced as a permanent change, but as a reward contingent on meeting a short-term project objective.

This is consistent with a specific aspect of Scanlon Principle \#4 that Lesieur also enjoyed pointing out to my students. He would say with a twinkle in his eye that in this type of situation even their ivory tower professor could be a successful consultant because any reward I might suggest for meeting some target was guaranteed to work. His point was that nearly any credible and fair reward for meeting a challenging time-specific objective has value, not perhaps so much to motivate employees who are already motivated to meet the challenge for professional and personal reasons, but to say a simple thank you in a highly tangible way.

One overriding conclusion from these cases is that perhaps there is no pay-for-performance plan that management is likely to dream up and implement unilaterally that will work. Pay is too important to be left to managers, HR professionals, and their consultants. There is no substitute for employee voice. Beer and Cannon note that there is always an implicit negotiation going on between the workforce and management as these plans are introduced. The challenge lies in making these implicit negotiations explicit and real. Until this happens, management and HR professionals will both be guessing at what employees are thinking and how they will respond and lack the credibility and independence to serve as the voice of the workforce.

Herein lies a dilemma for contemporary HR professionals. Management needs and employees want their own voice in the decisions that affect their interests but our generation of HR professionals has grown up in an era where an independent employee voice (i.e., a union or association) is viewed as an HR failure. Until the profession confronts and resolves this dilemma, most HRand management-led innovations are likely to experience a fate similar to the ones so nicely chronicled here.

Thomas Kochan is the George M. Bunker Professor of Management at the MIT Sloan School of Management. His research focuses on the changing nature of work and employment relationships and their implications for organizational governance and public policies. As co-director of the MIT Workplace Center, he is active in bringing together business, community, labor, and policy-making groups to coordinate efforts to better integrate work and family life. His most recent book is Working in America: A Blueprint for the New Labor Market.

\section{REFERENCES}

Lesieur, F. (1957). The Scanlon Plan. Cambridge, MA: MIT Press.
McKersie, R. B., \& Hunter, L. C. (1973). Pay, productivity, and collective bargaining. London: Macmillan. 


\section{"PROMISE AND PERIL IN IMPLEMENTING PAY- FOR-PERFORMANCE" BY MICHAEL BEER AND MARK D. CANNON}

\section{Commentary by Gerald E. Ledford Jr.}

The Beer and Cannon study of five out of 13 Hewlett-Packard pay-for-performance experiments examines management decision making in the adoption and abandonment of these plans. Their study offers several useful contributions. The authors provide information about multiple cases from the same company; they focus on implementation issues, which research and experience would suggest are more important than design in the success of such plans; and they provide the perspective of local managers who made decisions about the plans.

In commenting on the study, I argue that the author's findings are helpful but the conclusions about them are too broad, for three reasons. First, the article draws overly broad conclusions about "pay-for-performance" in general rather than on the specific plans that were used. Second, the criteria for determining success and failure of such plans are troublesome. Finally, there are some specific conditions facing HP that help explain the abandonment of the new pay programs that need greater emphasis.

\section{Definition of Pay-for-Performance}

The authors define pay-for-performance broadly as the linkage of monetary rewards to performance. This includes such diverse approaches as merit pay, production piece rates, team incentives, unit-level gain sharing, corporate profit sharing, and stock options. Note that this definition excludes skill-based pay, which provides incentives for learning rather than for performance. Incentive plans vary along many dimensions. For example, they vary according to the organizational level of the performance that is rewarded (individual, team, organizational unit, corporate) and the type of metrics used (behavioral, unit performance, accounting).

Definitions are important because the authors draw very broad conclusions about pay-for-performance and its compatibility with a high-commitment culture. However, at best, these conclusions should be limited to specific types of incentive plans that were the subjects of study. As the authors point out, HP had two types of pay-for-performance (corporate profit sharing and broadbased stock options) throughout the period of study, and these pay-for-performance plans were not considered incompatible with HP's culture. Indeed, these plans probably helped create the culture by encouraging a sense of common fate.

\section{Success Criteria}

The authors avoid drawing conclusions about objective success of the plans, but management decision making depends on the managers' views of success. The Workstations Group case appears to be an objective success-it was a short-term incentive that did what it was intended to do. In the 
other four cases, managers believed that employee disaffection warranted termination of the plan.

We are limited because HP did not systematically study employee attitudes about the plans. Any incentive plan is likely to generate employee "noise." What percentage of the workforce felt negatively about the plans? Was the noise at a "normal" level that should have simply prompted ongoing communication and the kind of negotiation the authors recommend, or was it so severe that it truly threatened the culture of the company? We do not know. One wonders whether the real weakness in the plans was in the managers who adopted them.

\section{Company-Specific Issues}

One of the most durable findings in the compensation research literature over the past 30 years is that such plans are most likely to be successful in high-commitment settings. Reviews of the gain-sharing and skill-based pay literatures have repeatedly confirmed this conclusion (see Heneman, Ledford, \& Gresham, 2000, cited by the authors). Therefore, we should be careful in concluding that pay-for-performance plans, or specifically gain-sharing and skill-based pay plans, are incompatible with a high-commitment culture.
Two factors other than culture are specific to HP and help explain the fate of its incentive plans. First, the rapid pace of change in products, production technologies, and organizational forms in the high-technology industry makes it very difficult to design sustainable local incentive plans. It is probably not an accident that the dominant incentives in high technology have been broad-based stock options and firmwide bonuses for corporate performance, which can be administered companywide with relative ease. Second, HP's absence of management bonuses until recently was unusual and was an unfavorable condition for incentives. Managers simply had no personal experience with the "noise" that accompanies incentive plans, or with the negotiation process that the authors correctly describe as essential to the success of such plans.

\section{Conclusion}

The study permits us to draw some firm conclusions about how managers perceived the plans and why they adopted and terminated the plans. The results show the importance of implementation processes and the need for incentives to fit their context. I am not convinced, however, that the cases imply an incompatibility of incentives with a highcommitment culture-as opposed to the specific culture of HP.

GERALD E. LEDFORD JR. is a nationally recognized authority on human capital issues, including compensation. He is president of the Ledford Consulting Network. From 1998 to 2003, he was at Sibson Consulting, where he was senior vice president. Previously, he was research professor at the Center for Effective Organizations (CEO), Marshall School of Business, University of Southern California, where he was a key contributor between 1982 and 1998. He received his PhD and MA in psychology from the University of Michigan. He is the author of 75 articles and ten books and monographs, most recently The Rewards of Work: The Employment Deal in a Changing Economy (2003). 


\section{"PROMISE AND PERIL IN IMPLEMENTING PAY FOR PERFORMANCE" BY MICHAEL BEER AND MARK D. CANNON}

\section{Commentary by Edwin A. Locke}

Beer and Cannon's case study of some HP incentive systems is an important piece of worksomething that should be done more often. It reinforces my belief that successful incentive systems, especially ones that work for the long term, are very hard, though not impossible (cf., Lincoln Electric, Nucor) to construct.

In my opinion, four of the five HP plans they reviewed were not very well designed. Here are some observations about mistakes that seem to have been made:

1. The use of team-based pay when the proper bonus unit perhaps should have been larger (cases 1 and 2). The individual teams evidently needed to cooperate in some ways (changing members, sharing information) but did not want to due to a possible threat to their bonuses.

2. Combining performance bonuses with skill-based pay (cases 1 and 2). It is confusing to have two types of incentive systems operating at once, especially given that the incentives are for quite different outcomes. And being rated by peers is very risky both from the point of view of using objective, consistent standards and from the point of view of psychology (resentment if you do not "pass," as occurred at HP).
3. Changing the standards (case 1 and perhaps case 2). Frederick W. Taylor, the father of task and bonus systems, warned against ever changing the bonus standards once set (Taylor, 1912/1967). Today we would say this violates the principles of both procedural and distributive justice. It was ironic that the incentives actually worked too well, in that teams did better than expected, which cost the company more money. However, this should have been anticipated because incentives are supposed to raise performance over past levels. Furthermore, if the improved performance helps make more money, this should benefit the company anyway. This raises the question of whether the performance measures were the right ones.

4. Non-control over performance (case $1)$. It is an axiom of incentive systems that the employees need to be able to control the outcomes for which they are paid. If outside factors interfere, this needs to be taken into account in designing the system.

5. The use of competition to determine bonuses (case 2). Competition may be beneficial in commission sales if cooperation between sales people is 
not needed, but it can be lethal if people need to cooperate.

6. Lack of sufficient employee knowledge (case 3). Incentives may motivate effort but they do not necessarily guarantee that the employees will have the knowledge needed to get the bonus. In this case, it seems, the employees needed coaching.

7. Bonuses too small (case 4). In this case, the bonuses of the acquired company did not get the employees to the level of HP pay, their apparent goal-a distributional justice problem.

It is interesting that the incentive plan worked very well in case 5 , even though it was a one-time-only event. This success may have been because it avoided the problems listed above, especially as it involved the whole project unit and presumably the employees had both knowledge and control. Furthermore, $60 \%$ of the employees favored using the same plan for other projects.

The general principle here is that incentive plans have to be designed very carefully (see Gerhart \& Rynes, 2003, for an excellent discussion of issues involved in incentive pay plans). It does not appear that HP thought the issue through very carefully nor did they seem to have learned everything they could have from their experience. I agree with Beer and Cannon that employee expectations are one aspect to consider in designing incentive plans, but they are not the whole story. One must also consider (as the authors do early in their article) how such plans will operate within and affect the wider system (e.g., the unit, the plant, the company), the employees' task knowledge, the stability of the produc- tion situation (static or dynamic), and the long-term consequences of the plan. It is also very important to know exactly what results you want the plan to produce; you may not get what you don't pay for (Gerhart \& Rynes, 2003). A poorly designed incentive system is usually worse than no system (other then merit pay), because it promotes bitterness and distrust, as Beer and Cannon note.

I am not fully convinced by Beer and Cannon's suggestion that incentive plans may be unsuitable within a high-commitment culture. Nor do I think it is fair to criticize Carly Fiorina's performance and her use of incentives, given that the entire high-tech industry took a huge hit over the previous three of four years and that HP's culture was, according to most observers, clearly in need of change. What they had was no longer working. The employees may have been committed but not necessarily to the right actions. The next three years will tell the tale about whether she has taken HP in the right direction or not.

A final remark about organizational change. Beer and Cannon argue that "flavor of the month" organizational change programs fail because they are pushed from the top. I disagree. I think they fail because they are not pushed from the top hard enough; they are introduced and then forgotten, then replaced by a new fad. In contrast, consider Jack Welch at GE (Locke, in press). He pushed Six Sigma and other change programs relentlessly from the top, basing manager bonuses on pushing the program, setting goals, and measuring progress quantitatively. He did get buy-in from lower levels, but only because he insisted that GE was going to make this change. This is a great topic for further study.

Edwin A. Locke is Dean's Professor of Leadership and Motivation (Emeritus) at the R. H. Smith School of Business at the University of Maryland, College Park. He has published over 240 books, chapters, and articles. He is internationally known for his research and writings on work motivation, leadership, and related topics, including the application of objectivism to psychology and management. He is a Fellow of the American Psychological Association, the American Psychological Society, and the Academy of Management, and has received many scholarly awards. He is a senior writer for the Ayn Rand Institute and has published numerous op-eds. 


\section{REFERENCES}

Beer, M., \& Cannon, M. (2004). Promise and peril in implementing pay-for-performance. Human Resource Management Journal, 43, 3-20.

Gerhart, B., \& Rynes, S. (2003). Compensation: Theory, evidence, and strategic implications. Thousand Oaks, CA: Sage.
Locke, E. (in press) The leader as integrator: The case of Jack Welch at General Electric. In L. Neider \& C. Schriesheim (Eds.), Research in management. Greenwich, CT: Information Age Publishing.

Taylor, R. (1967). The principles of scientific management. New York: Norton. (Original work published 1912) 


\section{RESPONSE TO COMMENTS: "PROMISE AND PERIL IN IMPLEMENTING PAY- FOR-PERFORMANCE"}

\section{Michael Beer and Mark D. Cannon}

The decision of managers in 12 out of 13 organizational units at Hewlett-Packard to abandon pay-for-performance (PFP) systems they (not corporate management) initiated seemed to us to be an important story to report, particularly given the overwhelming conventional wisdom in both the business and academic community that PFP systems are a model of motivation managers should adopt. Enthusiasm for PFP is too often not accompanied by warnings about difficulties and risks, something that all of the commentators acknowledged.

Gerry Ledford correctly cautions that there are many different PFP systems and that they "vary according to the organizational level of performance that is rewarded (individual, team, organizational unit and corporate)" and type of outcomes measured (behavioral and business performance). We would add that PFP systems also differ in how tightly pay is coupled to performance (based on objective measure or on managerial judgment). These are important distinctions. We should have been clearer that we were generalizing to the same class of PFP systems employed at HP, tightly coupled PFP systems tied to business performance aggregated at the individual, team, or unit level (when those units are interdependent). As Ledford points out, HP had long used a corporate-level profit-sharing plan and stock options quite successfully.

We saw this as a story about implementation failure, not a story that informs the question of whether PFP can motivate behavior, although an argument could be made, as Douglas McGregor (1960) did, that pay-for-performance moves (external control) but does not motivate (internal control) people. We are gratified that all the commentators welcomed our focus on implementation and felt that failure was as important to document as success. All agreed that the cases raised contribute to our knowledge about pay-for-performance systems.

Many of the commentators justifiably voiced concern about our capacity to draw definitive conclusions from these cases. We agree with this concern and were quite aware from the beginning that these cases could not definitively adjudicate the question of whether the costs of tightly coupled individual and team incentives outweigh their benefits. This is a fundamentally important question that we do not believe has been adequately addressed by researchers. Cases like this do, however, highlight issues that are underresearched and questions that we cannot answer. Given the lack of systematic data collected by the company at the time and our limited retrospective interviews, the interpretation of these cases depends in part on the frame the reader uses. It is not surprising, therefore, that the seven commentators had different reactions to our article and different explanations for the PFP failures, though there were many overlapping points. We saw three different primary frames being applied in explaining the failures. They were:

1. Unit managers' lack of knowledge about how to design and implement PFP. 
... we disagree with the implication that if the managers had just been a bit smarter and more experienced in designing and implementing PFP, these problems could have been avoided.
2. Tightly coupled individual and group incentives did not fit the highcommitment culture of HewlettPackard, a company that historically had eschewed instrumental incentive systems.

3. Local unit managers' failure to involve their employees in the decision to adopt PFP, its design, and solving the problems of implementation.

All three frames are reasonable ways to evaluate what happened at HP. All three explanations probably account for why the PFP initiatives were abandoned. What we don't understand is the relative importance and interaction of these three frames of reference in explaining success and failure. Below we discuss these three interpretations of PFP and along the way we also respond to a few misinterpretations of our assertions.

1. Unit managers lacked knowledge about how to design and implement PFP. We were struck by how much agreement there was about how difficult it is to design and implement PFP. Unfortunately, few consultants give this warning to managers and few academics frame their research in a way that enables an assessment of the costs associated with PFP (Gerhart's work is an exception). We agree with Locke, Heneman, and Dailey that the failure to implement PFP effectively can be attributed to a number of "familiar problems," as Heneman says. And we agree with most of the factors cited: changes in standards of performance (Locke reminds us that Frederick Taylor warned against this and Kochan tells us that Lesieur did as well), the lack of control by employees over factors that affected performance, the appropriate design of performance measures, the use of peer evaluation, insufficient payouts, and the lack of knowledge by managers about PFP and communication to employees about PFP. All commentators agreed that an uncertain and changing environment exacerbates the problem of designing and implementing PFP, but only Kochan's discussion of participation and negotiation went beyond the recommendation of simply better anticipation.

While we believe all these and many other factors did indeed undermine the success of the HP pay initiatives, we disagree with the implication that if the managers had just been a bit smarter and more experienced in designing and implementing PFP, these problems could have been avoided. Heneman speculates, for example, that if the employees had received better training, there had been better communication, and the human resource function had been more involved, these failures would not have occurred. We have heard these refrains about better design and implementation from advocates of PFP many times but are skeptical. There are simply too many PFP failures to be explained away by poor design and poor implementation. PFP advocates and researchers, we think, have ignored the risks and costs associated with PFP, as Gerhart has also suggested. It seems to us, just as it appeared to the managers at HP, that in many instances the cost (time and money) of designing and redesigning PFP systems, low morale, employee focus on pay rather than the competitive task, loss of flexibility, and reduced teamwork make PFP a far less universal answer to management's search for high performance than normally assumed. Kochan reminds us that McKersie and Hunter (1973) found that "there is a powerful tendency for all incentives to deteriorate," which means of course that they must be redesigned and renegotiated over and over again. Elsewhere, Beer and Katz (2003) found the same effect for executive incentive systems. We do not disagree with Heneman that more communication, training, and support from the 
human resource function would have helped, but these have to be added to the cost side of the equation.

2. The choice of PFP design did not fit the high-commitment culture at Hewlett-Packard. Underlying the critique by Locke, Heneman, and Dailey, discussed above, is the implication that the difficulties with tightly coupled PFP must be overcome at all cost because such systems are essential for high performance. They seem to reject our speculations that PFP failed because it did not fit HP's high-commitment culture. Baron and Gerhart, on the other hand, supported this view. We do not agree with Ledford's view that a wide body of research has shown that tightly coupled PFP plans are more likely to be successful in high-commitment organizations. For example, Pfeffer (1998), in his book The Human Equation, concludes that high-commitment and performance companies typically aggregated PFP at the organizational level, not at the individual or group level. The findings of the GLOBE project discussed by Baron support the idea that companies choose an array of practices that fit together. Firms that utilize instrumental mechanisms such as process, measurement, and incentives as control mechanisms tended not to employ strategy, networks, and culture as means of control and vice versa. The Stanford research into the HRM systems of high-technology companies of which Baron has been a part also found that HRM systems align and they align around the assumptions and beliefs of the founder or successor CEO (Baron, Burton, \& Hannan, 1996). According to this research, fit trumps someone else's best practice.

It seemed to us that the noise level about PFP and lowered trust at HP that caused management to abandon the team-based bonus systems reflected the fit principle.
Ledford suggests that managers inexperienced in managing instrumental PFP systems may have overreacted. But it may also be true, as we argued, that they reacted to lowered trust and commitment more aggressively then other managers because they saw these qualities in their relationship with employees as valuable assets to be protected. Our discussion of Fiorina's transformation of HP away from a high-commitment system years later and the noise levels and shortfall in performance that followed was intended to illustrate a contrasting approach within the same company, one that indeed did damage HP's high-commitment system. It was also intended to show that PFP does not necessarily lead to higher performance. We were not confused, as Dailey seems to suggest, about the fact that these were independent events motivated by different change agendas.

Pay-for-performance researchers and consultants too often start with the premise that pay-for-performance systems are desirable as opposed to helping managers answer a more fundamental question first: What are your assumptions, value, and strategy, and, therefore, what kind of HRM system do you want to build? The literature does discuss strategy, but values and assumptions are not given sufficient weight. Having helped managers with this fundamental choice, decisions about PFP can be made much more cogently. A legitimate goal of PFP might simply be fair pay, a goal Lesieur reminded Kochan's students is essential for PFP success. Other means such as work itself, involvement, leadership, and culture can also provide rewards for performance, though these are less instrumental. Underlying assumptions about motivation and pay reflect assumptions about the nature of "man," as McGregor (1960) pointed out. Decisions about how to design

\author{
A legitimate \\ goal of PFP \\ might simply be \\ fair pay...
}


PFP reflect these assumptions and influence the emerging HRM system. And, of course, if the HRM system has been set up with Theory $\mathrm{X}$ assumptions, it probably means that only Theory X pay-for-performance systems (pay tightly coupled to measurable goals) will fit. As Baron suggests, ideal organizational types, whether they are based on soft or hard control systems, may be more effective then HRM systems that try to mix these approaches. Compensation research has not engaged these questions adequately to date. It has almost completely ignored the underlying character of the HRM system as an important contextual factor.

3. Failure of local unit managers to involve their employees in decisions about the new PFP system. All commentators agreed that an uncertain environment poses major challenges for all PFP systems. Tom Kochan reminded us, using lessons learned by Fred Lesieur in implementing Scanlon Plans, that participation in PFP design and implementation by those affected is a key to success. As we said in the article, participation and negotiation are the overarching principles for successful implementation. As Lesieur suggests, participation in the decision to adopt the plan, in its design, in potential changes to the PFP plan, and in its administration are essential. Without it, employees will come to see the inevitable changes

\section{REFERENCES}

Baron, J. N, Burton, D. M., \& Hannan, M. T. (1996). The road taken: Origins and evolution of employment systems in emerging companies. Industrial and Corporate Change, 2, 239-275.

Beer, M., \& Katz, N. (2003). Do incentives work? The perceptions of a worldwide sample of se- in standards of performance and payout as unfair. Such participation is, of course, a cost that must be weighed against the benefits of PFP. It seems to us that management is often attracted to the promise of PFP without considering the risks and costs involved in participation, probably because, as Kochan points out, employee voice has fallen out of fashion. The costs do not show up until later. What the tradeoffs are between top-down introduction and participation in PFP design requires further research.

These three different frames applied by experts in the field suggest that our current understanding of PFP is incomplete. Future research into the success and failure of PFP introductions must collect data within all three frames - design and implementation, fit of the system with the culture, and the extent of employee participation. Without understanding PFP through all three lenses, we are unable to advise management competently. If there is one thing we can learn from the different assessments of these cases it is that attributing failure to managers' lack of competence in anticipating potential problems when designing PFP is an oversimplification. As Baron suggests, the conditions that make PFP "especially desirable or feasible, paradoxically, make it especially tough to implement." This is probably why some companies concerned about trust and commitment generally eschew instrumental PFP systems except in situations that are most favorable to effective implementation over time.

nior executives. Human Resource Planning, 26(3), 30-44.

McGregor, D. (1960). The human side of the enterprise, New York: McGraw-Hill

McKersie, R. B., \& Hunter, L. C. (1973). Pay, productivity, and collective bargaining. London: Macmillan.

Pfeffer, J. (1998). The human equation. Boston: Harvard Business School Press. 